\title{
Clonal dynamics of SARS-CoV-2-specific T cells in children and adults with COVID-19
}

Weng Hua Khoo ${ }^{1,2}$, Katherine Jackson ${ }^{1}$, Chansavath Phetsouphanh ${ }^{3}$, John J. Zaunders ${ }^{4}$, José Alquicira-Hernandez ${ }^{5,6}$, Seyhan Yazar $^{5}$, Stephanie Ruiz-Diaz ${ }^{1}$, Mandeep Singh ${ }^{1,2}$, Rama Dhenni ${ }^{1,2}$,

Howard-Jones $^{9}$, Archana Koirala ${ }^{9}$, Li Zhou ${ }^{9}$, Aysen Yuksel ${ }^{9}$, Daniel R. Catchpoole ${ }^{9,10}$, Catherine L. Lai $^{9}$, Tennille L. Vitagliano ${ }^{9}$, Romain Rouet ${ }^{1,2}$, Daniel Christ ${ }^{1,2}$, Benjamin Tang ${ }^{11,12,13}$, Nicholas P. West $^{14}$, Shane George ${ }^{15,16}$, John Gerrard ${ }^{17}$, Peter I. Croucher ${ }^{1,2}$, Anthony D. Kelleher ${ }^{3}$, Christopher G. Goodnow ${ }^{1,2,18}$. Jonathan D. Sprent ${ }^{1,2}$, Joseph D. Powell ${ }^{5,18}$, Fabienne Brilot ${ }^{7,19,20}$, Ralph Nanan ${ }^{21}$, Peter S. Hsu ${ }^{9,10}$, Elissa K. Deenick ${ }^{1,21}$, Philip N. Britton ${ }^{8,22,23}$, Tri Giang Phan ${ }^{1,2}$

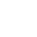

${ }^{1}$ Garvan Institute of Medical Research, Sydney, Australia;
${ }^{2}$ St Vincent's Clinical School, Faculty of Medicine, UNSW Sydney, Sydney, Australia;
${ }^{3}$ Kirby Institute, UNSW Sydney, Sydney, Australia;
${ }^{4}$ Centre for Applied Medical Research, St Vincent's Hospital, Sydney, Australia;

${ }^{5}$ Garvan-Weizmann Centre for Cellular Genomics, Garvan Institute of Medical Research, Sydney, Australia;

${ }^{6}$ Institute for Molecular Bioscience, University of Queensland, Brisbane, Australia;

${ }^{7}$ Brain Autoimmunity Group, Kids Neuroscience Centre, Kids Research at the Children's Hospital at Westmead, Sydney, Australia;

${ }^{8}$ Sydney Medical School, Faculty of Medicine and Health, University of Sydney, Sydney, Australia;

${ }^{9}$ Kids Research, The Children's Hospital at Westmead, Sydney, Australia;

${ }^{10}$ Discipline of Child and Adolescent Health, The University of Sydney, Sydney, Australia;

${ }^{11}$ Department of Intensive Care Medicine, Nepean Hospital, Sydney, Australia;

${ }^{12}$ Centre for Immunology and Allergy Research, The Westmead Institute for Medical Research, Sydney, Australia;

${ }^{13}$ Respiratory Tract Infection Research Node, Marie Bashir Institute for Infectious Diseases and Biosecurity, Sydney, Australia;

${ }^{14}$ Systems Biology and Data Science, Menzies Health Institute QLD, Griffith University, Parklands, Australia;

\footnotetext{
${ }^{15}$ Departments of Emergency Medicine and Children's Critical Care, Gold Coast University Hospital, Southport, QLD, Australia;

${ }^{16}$ School of Medicine and Menzies Health Institute Queensland, Griffith University, Southport, QLD, Australia;
} 
${ }^{17}$ Department of Infectious Diseases and Immunology, Gold Coast University Hospital, Southport, QLD, Australia;

${ }^{18}$ UNSW Cellular Genomics Futures Institute, UNSW Sydney, Sydney, Australia;

${ }^{23}$ The Children's Hospital at Westmead, Sydney Children's Hospitals Network, Sydney, Australia. 43 


\section{SUMMARY}

49 Children infected with severe acute respiratory syndrome coronavirus 2 (SARS-CoV-2) develop less severe coronavirus disease 2019 (COVID-19) than adults. The mechanisms for the age-specific

51 differences and the implications for infection-induced immunity are beginning to be uncovered. We

52 show by longitudinal multimodal analysis that SARS-CoV-2 leaves a small footprint in the 53 circulating $\mathrm{T}$ cell compartment in children with mild/asymptomatic COVID-19 compared to adult 54 household contacts with the same disease severity who had more evidence of systemic $\mathrm{T}$ cell 55 interferon activation, cytotoxicity and exhaustion. Children harbored diverse polyclonal SARS-CoV56 2-specific naïve T cells whereas adults harbored clonally expanded SARS-CoV-2-specific memory $\mathrm{T}$ cells. More naïve interferon-activated $\mathrm{CD}^{+} \mathrm{T}$ cells were recruited into the memory compartment and recovery was associated with the development of robust $\mathrm{CD} 4^{+}$memory $\mathrm{T}$ cell responses in adults

59 but not children. These data suggest that rapid clearance of SARS-CoV-2 in children may 60 compromise their cellular immunity and ability to resist reinfection.

\section{HIGHLIGHTS}

- Children have diverse polyclonal SARS-CoV-2-specific naïve T cells

- Adults have clonally expanded exhausted SARS-CoV-2-specific memory T cells

- Interferon-activated naïve T cells differentiate into memory T cells in adults but not children

- Adults but not children develop robust memory T cell responses to SARS-CoV-2 


\section{Children}

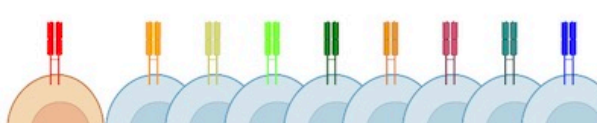

Acute

Diverse polyclonal SARS-CoV-2 naive T cells

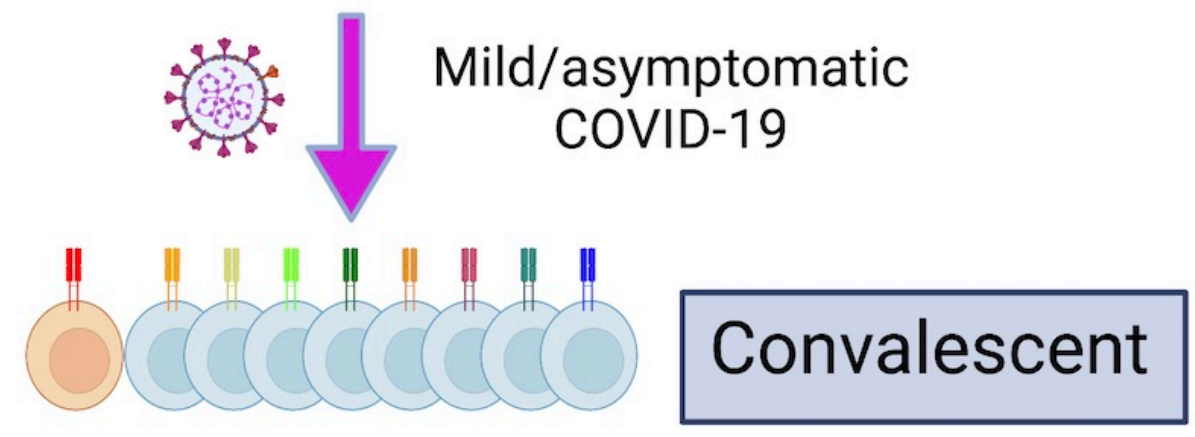

Sub-optimal activation | Poor T cell memory

\section{Adult}

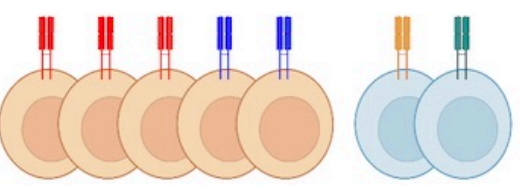

Acute

Clonally expanded SARS-CoV-2 memory T cells

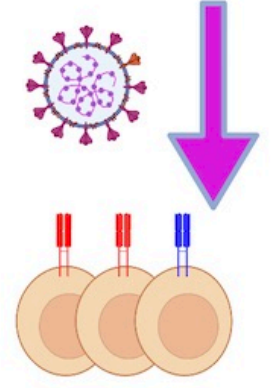

Mild/asymptomatic COVID-19

Convalescent

Narrowing of TCR repertoire | New memory T cells 


\section{Introduction}

70 Infection with the respiratory pathogen severe acute respiratory syndrome coronavirus 2 (SARSCoV-2) causes the pandemic coronavirus disease 2019 (COVID-19) (Guan et al., 2020; Zhou et al., 2020). Disease severity varies widely from asymptomatic infection in the majority of individuals, to severe life-threatening disease in a minority of patients (Chen et al., 2020; Huang et al., 2020; Wang et al., 2020). Older age, male sex and comorbidities such as hypertension, cardiovascular disease and diabetes have been identified as independent risk factors for severe disease and death (Jordan et al., 2020). There is now consistent evidence across multiple different settings and locations that the severity of COVID-19 infection increases substantially with age (O'Driscoll et al., 2021). '

Recently, a number of investigators have examined the local and systemic immune responses of children to SARS-CoV-2 to determine the potential mechanisms for these age-specific differences in susceptibility to infection and disease. Most notably, it has been shown that children have an enhanced antiviral sensing and stronger antiviral interferon response in the upper airways due to higher basal expression of the MDA5 and RIG-1 viral pattern recognition receptors and interferon gene signatures in nasal epithelial cells, macrophages and dendritic cells (Loske et al., 2021; Yoshida et al., 2021). This pre-activated innate immune system may be more efficient at clearing SARS-CoV-

2 infection. Indeed, analysis of three child household contacts of adults with PCR-confirmed symptomatic COVID-19 suggested that children may mount an effective early antiviral immune response that eliminates the virus without any detected PCR evidence of SARS-CoV-2 infection (Tosif et al., 2020). These differences in the innate immune response of children may also be detectable in the immunophenotype of circulating neutrophils, dendritic cells, monocytes and natural killer (NK) cells in the peripheral blood (Neeland et al., 2021).

The adaptive immune response to SARS-CoV-2, particularly the humoral component provided by antibodies and memory B cells, can be either protective or pathogenic in COVID-19 (Bartsch et al., 2021; Zohar and Alter, 2020). There is evidence that antibodies against endemic human coronaviruses (hCoV) cross-react with SARS-CoV-2 and these may be back-boosted upon infection (Anderson et al., 2021; Aydillo et al., 2021; Ng et al., 2020). However, this pre-existing cross-reactive humoral immunity does not appear to provide protection, and may potentially be harmful by locking in the memory B cell responses and preventing the emergence of de novo naïve $\mathrm{B}$ cell responses to novel SARS-CoV-2 antigens, a phenomenon known as original antigenic sin (Aydillo et al., 2021; Dhenni and Phan, 2020; Francis, 1960; Zhang et al., 2019). Analysis of pre-pandemic serum has also shown that healthy elderly individuals have higher immunoglobulin class-switched IgA and IgG antibodies that cross-react with SARS-CoV-2, whereas children have elevated cross-reactive SARS-CoV-2 IgM 
antibodies (Selva et al., 2021), suggesting that they have less exposure to hCoV and are less antigenexperienced but more polyreactive. Furthermore, it has been suggested that pathogenic responses associated with severe COVID-19 are linked to SARS-CoV-2 IgA and neutrophil hyperactivation (Bartsch et al., 2021) and that the antibodies produced by children differ from adults in their Fcdependent antibody effector functions such as antibody-dependent cellular cytotoxicity, phagocytosis and complement activation (Bartsch et al., 2021; Selva et al., 2021).

There is emerging evidence that cellular immunity against SARS-CoV-2 provided by T cells may be similarly impacted by prior exposure to $\mathrm{hCoV}$. Using overlapping peptide pools for in vitro $\mathrm{T}$ cell stimulation assays, investigators have detected $\mathrm{CD} 4^{+}$and $\mathrm{CD} 8^{+} \mathrm{T}$ cells cross-reactive against SARSCoV-2 spike (S), membrane (M), nucleocapsid (N) and open reading frames (ORF) in pre-pandemic blood samples from unexposed individuals (Bacher et al., 2020; Braun et al., 2020; Grifoni et al., 2020; Le Bert et al., 2020; Mateus et al., 2020). Consistent with this, SARS-CoV-2 T cell responses have been shown to be lower in children and increase with age and time after infection (Cohen et al., 2021).

We performed longitudinal analysis of the immune response of seven children and five adults from the same household with mild/asymptomatic COVID-19 in the community confirmed by reverse transcription polymerase chain reaction (RT-PCR) and an additional two unrelated adults who were ventilated in the intensive care unit with severe life-threatening COVID-19. We analyzed the cellular phenotype, serum antibody response to SARS-CoV-2, cytokine profile, in vitro memory $\mathrm{T}$ cell responses to recombinant $\mathrm{S}$ and RBD proteins, and simultaneous single cell transcriptome and TCR and $\mathrm{B}$ cell receptor (BCR) repertoire sequencing of 433,301 single cells obtained from acute and convalescent blood samples. These multimodal analyses identified novel subpopulations of naïve $\mathrm{T}$ cells, including acutely expanded clusters of interferon-activated naïve $\mathrm{T}$ cells which differentiate into memory $\mathrm{T}$ cells in convalescence. We show that mild/asymptomatic COVID-19 results in systemic activation of both the innate and adaptive immune compartments in adults. In contrast, children had less activation of the circulating T and B cells. Children have more SARS-CoV-2specific T cells which predominantly have a naïve phenotype and diverse TCR repertoire. Adults have fewer SARS-CoV-2-specific T cells which are more antigen-experienced and often harbor clonally expanded exhausted memory $\mathrm{T}$ cells. Circulating $\mathrm{T}$ cells in children retain their naïve state and did not generate many antigen-specific memory $\mathrm{T}$ cells despite infection with the virus. In contrast, adults generated more memory $\mathrm{T}$ cells from the naïve interferon-activated and this was associated with the development robust SARS-CoV-2-specific memory $\mathrm{T}$ cell responses in adults, 
138 but not children. This failure of infection-induced immunity places children at the risk of recurrent

139 infection and progressive restriction of their $\mathrm{T}$ cell repertoire and responses as they grow older.

\section{RESULTS}

\section{Longitudinal tracking of the immune response to SARS-CoV-2 in children and adults}

Acute and convalescent blood samples from seven children $(<16$ years of age) and five adults $(>30$

years of age) with mild/asymptomatic disease (WHO Clinical Progress Scale of 0 or 1 out 10), and two adults who were intubated and ventilated in the intensive care unit (ICU) with severe disease (WHO Clinical Progress Scale of 7 out of 10) were analyzed (Fig. 1A, 1B). Two of the children (C3 and C4) were identical twins. Both children and adults developed antibodies to S protein in the convalescent phase, with the highest antibody titres detected in the ICU adults (Fig. 1C). High dimensional flow cytometry showed consistent differences in the distribution of circulating natural killer (NK) cells, naïve and memory B and T cells that reflected age-specific differences between children and adults (Fig. S1). Nevertheless, there was evidence of increased T cell activation in the acute stage with 2 -fold expansion of activated CD38 ${ }^{+} \mathrm{HLA}_{-} \mathrm{DR}^{+} \mathrm{CD} 4^{+} \mathrm{T}$ cells and 3 -fold expansion of $\mathrm{CD} 38^{+} \mathrm{HLA}-\mathrm{DR}^{+} \mathrm{CD}^{+} \mathrm{T}$ cells in non-ICU adults compared to children (Fig. 1D). ICU adults had the highest frequency of CD38 ${ }^{+} \mathrm{HLA}-\mathrm{DR}^{+} \mathrm{T}$ cells. Serum cytokine analysis detected 50 - to 100 -fold elevation of interleukin-6 (IL-6) in the ICU adults compared to acute children, convalescent children, acute non-ICU adult and convalescent non-ICU adult $(p=0.001$, one-way ANOVA with Tukey's corrections) (Fig. 1E).

We next generated single cell transcriptomes from acute and convalescent samples from these 14 COVID-19 patients. In total, we sequenced 522,926 cells and excluded samples from two patients (C7 and A11 from the same household) due to batch effects (Fig. S1C). The remaining 433,301 cells were visualized in 2D Euclidean space by uniform manifold approximation and projection (UMAP)

(Fig. 1F). We initially annotated clusters of cells which consisted of populations of 69,074 B lineage cells, 171,393 $\mathrm{CD}^{+} \mathrm{T}$ cells, 127,069 $\mathrm{CD}^{+} \mathrm{T}$ cells, 376 dendritic cells (DCs), 4,135 monocytes, 56,807 NK cells, and 4,447 other cell types (including HSCs, platelets, erythrocytes and doublets) (Fig. 1G and Fig. S2). Analysis of the cellular composition identified similar age-specific changes to the circulating NK, B and T cell populations as observed by the flow cytometry (Fig. 1G and Table immune compartments in children and adults, there is evidence for greater systemic $\mathrm{T}$ cell activation in adults. 
173 We resolved the circulating innate and adaptive immune compartments in children and adults into 174 populations of DCs (plasmacytoid dendritic cells, pDC; $\mathrm{AXL}^{+} \mathrm{SIGLEC6}^{+}$dendritic cells, ASDCs; 175 type 2 conventional dendritic cell, cDC2), NK cells (proliferating; CD56 ${ }^{\text {dim; }}$ CD56 $6^{\text {bright }}$ ), monocytes $176\left(\mathrm{CD}_{14}^{+} ; \mathrm{CD} 16^{+}\right)$, other cells (platelets; erythroblasts; HSPCs; innate lymphoid cells, ILCs; doublets), 177 B lineage cells (naïve, memory, intermediate and plasmablasts), CD4 ${ }^{+} \mathrm{T}$ cells (naïve; stressed naïve; 178 transcriptionally active naïve; interferon-activated naïve; $C D 40 \mathrm{LG}^{+}$naïve; early memory; effector 179 memory (TEM); early memory and regulatory T cells (Treg), and CD8 ${ }^{+} \mathrm{T}$ cells (naïve; PECAM-1 ${ }^{+}$ 180 naïve; interferon-activated naïve; TEM; GZMK ${ }^{+}$TEM; CD20 ${ }^{+}$TEM; cytotoxic; KLRB1 ${ }^{+}$cytotoxic 181 T cells) (Fig. 2A). Semi-automated annotation of the T cell compartment based on the expression of 182 canonical genes revealed marked heterogeneity, particularly in the naïve $\mathrm{T}$ cell compartment with several previously unappreciated subpopulations of naïve $\mathrm{CD}^{+}$and $\mathrm{CD} 8^{+} \mathrm{T}$ cells that showed evidence of TCR-independent bystander activation by upregulation of CD40LG, stress-induced genes, transcriptional activity and interferon-induced genes (Fig. 2B). Analysis of the genes expressed by the different $\mathrm{T}$ cell clusters revealed interferon-activated naïve $\mathrm{CD} 4^{+}$and $\mathrm{CD} 8^{+} \mathrm{T}$ cells express a number of interferon-induced genes including IFI44L, MX1, ISG15, IRF7 and OAS1 (Fig. 2B and Table S2). Similarly, we identified a number of memory and effector subpopulations including $\mathrm{CD}^{+} \mathrm{GZMK}^{+} \mathrm{TEM}$ and $\mathrm{KLRB}^{+}$cytotoxic cells based on their transcriptional profile and TCR receptor usage. $\mathrm{CD}^{+} \mathrm{GZMK}^{+} \mathrm{TEM}$ are a newly described subset of exhausted-like memory $\mathrm{T}$ cells expressing TOX, TIGIT, FGFBP2, TBX21, SLAMF7, ZEB2, NKG7, GZMH and PRF1 (Table S2) that give rise to dysfunctional, exhausted effector T cells (Galletti et al., 2020). KLRB1 ${ }^{+}$cytotoxic

$\mathrm{T}$ cells include MR1-restricted mucosal-associated invariant $\mathrm{T}$ (MAIT) cells expressing TRAV1/TRAJ33 and IL-17-producing cytotoxic T cells (Tc17) expressing MAF, RORC, TBX21, EOMES, IL18R1, CCR6, PRF1, GZMK, GZMA, NKG7, CST7 and GNLY (Table S2). KLRB1 ${ }^{+}$ cytotoxic T cells are reported to be tissue-homing IL-17A producing cells (Billerbeck et al., 2010); however, we did not detect upregulated expression of $I L 17 A$ or related IL-17 family genes.

Intracellular flow cytometry confirmed the upregulated expression of the interferon-inducible MX-1 protein in a number of cell types, including naïve $\mathrm{CD} 4^{+}\left(\right.$Fig. 2C) and $\mathrm{CD} 8^{+} \mathrm{T}$ cells (Fig. 2D), particularly in the acute phase. To determine if these subpopulations of naïve $\mathrm{T}$ cells were unique to COVID-19 or were also present in individuals who had not been exposed to SARS-CoV-2, we examined the distribution of $\mathrm{T}$ cells in age-matched PBMCs from the OneK1K cohort which was collected pre-2019 (Fig. 2E). This analysis showed that these novel interferon-activated naïve CD4 ${ }^{+}$ and $\mathrm{CD}^{+} \mathrm{T}$ cells are also present in healthy adults who have not been infected with SARS-CoV-2. Thus, the circulating $\mathrm{T}$ cell compartment in children and adults is heterogeneous with multiple 
previously unrecognized subpopulations of naïve and activated $\mathrm{T}$ cells, including interferon-activated naïve $\mathrm{CD}^{+}$and $\mathrm{CD} 8^{+} \mathrm{T}$ cells.

\section{Differential gene expression between children and adults infected with SARS-CoV-2}

211 We analyzed for differentially expressed genes (DEGs) between each subpopulation to determine the 212 differences between children and non-ICU adults who both had mild/asymptomatic COVID-19. We 213 detected very few DEGs in the adaptive B and T cell compartments in children compared to adults 214 as they transitioned from acute to convalescence (6 upregulated, no downregulated genes in children; 21522 upregulated, 43 downregulated genes in non-ICU adults; $p=0.003$, Fisher's exact test) (Fig. 3A). 216 In contrast, there were a large number of DEGs in the innate NK cell and monocyte compartment in 217 both groups (25 upregulated, 24 downregulated genes in children; 67 upregulated, 50 downregulated 218 genes in non-ICU adults; $p=0.285$, Fisher's exact test). Notably, there was upregulation of interferon219 induced genes (e.g. IFI66, IFI44L and XAF1) during acute infection and mitochondrial oxidative 220 phosphorylation (OXPHOS) genes (e.g. MT-ATP6, MT-CYB, MT-ND4 and MT-CO1) upon recovery 221 (Fig. S2). In contrast, there were a large number of differentially expressed genes in both the innate 222 and adaptive immune compartments in non-ICU adults (Fig. 3A). Notably, there was significant 223 upregulation of interferon-induced genes in the $\mathrm{B}, \mathrm{CD}^{+}$and $\mathrm{CD}^{+} \mathrm{T}$ cell compartments, as well as 224 the NK cell and monocyte compartments, during acute infection, and upregulation of OXPHOS genes upon recovery (Fig. S2). Direct comparison of acute children and acute non-ICU adult PBMCs revealed the largest differences were in the monocyte and $\mathrm{CD} 8^{+} \mathrm{T}$ cell compartment $(\mathbf{F i g}$. $\mathbf{3 A}$ and Fig. S2). There was upregulation of naïve/T memory stem cell genes (e.g. IL 7R, LEF1, NOSIP, SELL and $T C F 7$ ) in $\mathrm{CD}^{+} \mathrm{T}$ cells in children and upregulation of cytotoxicity genes (e.g. CST7, GNLY, GZMA, GZMB, GZMH, NKG7 and PRF1) in non-ICU adults. These acute gene expression differences between children and non-ICU adults in the $\mathrm{CD} 8^{+} \mathrm{T}$ cell compartment were less prominent but nevertheless persisted into convalescence (Fig. S2). We next performed DGE analysis on each cell subpopulation (Fig. 3B). There was a significant number of differentially expressed genes for all cell clusters except for the DC subsets and the interferon-activated naïve $\mathrm{CD} 8^{+} \mathrm{T}$ cells. Importantly, greater gene expression differences were observed in non-ICU adults than in children,

The most consistently upregulated genes were interferon-induced genes. We therefore generated an interferon gene signature (Table S3), and scored each cell subpopulation in children, non-ICU adults and ICU adults (Fig. 3C and 3D). These data confirmed the high expression of interferon-induced genes, particularly in the monocyte subpopulations and novel interferon-activated naïve $\mathrm{CD}^{+}$and 
convalescent phase, and was higher in non-ICU adults than children. These data show that SARSCoV-2 infection leaves a more profound immunological footprint, especially in the adaptive $\mathrm{B}$ and $\mathrm{T}$ cell compartments, in adults compared to children with the same disease severity.

\section{Differences between SARS-CoV-2-specific $\mathbf{T}$ cells in children and adults}

We next analyzed the $158,975 \mathrm{CD}^{+} \mathrm{T}$ cells and $105,273 \mathrm{CD}^{+} \mathrm{T}$ cells where we were able to sequence and reconstruct the TCR. There was similar clonal diversity in the $\mathrm{CD}^{+} \mathrm{T}$ cell compartment in children and adults as measured by Shannon Entropy index (Fig. 4A). However, there were significant differences in the $\mathrm{CD} 8^{+} \mathrm{T}$ cell compartment where children had the most diverse TCRs followed by non-ICU adults and then ICU adults (Fig. 4A). Within each group the diversity did not differ between acute and convalescent timepoints. TCR sequences were annotated using ImmuneCODE (Nolan et al., 2020) and VDJdb (Bagaev et al., 2020), large-scale databases of TCR sequences and binding associations with the addition of SARS-CoV-2 TCR sequences reported in the literature and the SARA-CoV-2-annotated cells mapped on to the T cell clusters in the UMAP for children, non-ICU adults and ICU adults (Fig. 4B). The ImmuneCODE database aggregates $>135,000$ TCR sequences that have been shown with high confidence to react against SARS-CoV-2, while VDJdb collects and curates TCRs of diverse specificity from direct submissions and mining of the literature. These databases do not represent the full landscape of SARS-CoV-2 specificity as they are highly dependent on the peptide pools used to stimulate the T cells. We therefore sought to explore additional SARS-CoV-2 responding T cells within our donors by bulk TRB sequencing pools of proliferated $\mathrm{T}$ cells that had been stimulated with recombinant $\mathrm{S}$ and RBD proteins. Clonotypes with enriched frequencies after in vitro antigen-specific expansion were considered to have putative SARS-CoV-2 specificity (Table S4). In total, we annotated significantly more SARS-CoV-2specific $T$ cells in children (431 of 81,686 in acute and 474 of 84,567 cells in convalescence) than non-ICU (209 of 46,216 in acute and 196 of 49,620 in convalescence) and ICU adults (132 of 17,081 in acute and 102 of 19,292 in convalescence) $\left(\mathrm{p}<0.0001\right.$, Fisher's exact test). We matched $746 \mathrm{CD}^{+}$ and $798 \mathrm{CD}^{+} \mathrm{T}$ cells in our dataset that were potentially reactive against the envelope, surface glycoprotein, membrane glycoprotein, nucleocapsid phosphoprotein, ORF1ab, ORF3a, ORF6, ORF7a, ORF7b, ORF8 and ORF10 of SARS-CoV-2 (Fig. 4C and 4D). Children harbored more SARS-CoV-2-annotated CD4 ${ }^{+} \mathrm{T}$ cells (mean 76 cells, 74 clones) than non-ICU (mean 49 cells, 49 clones) and ICU adults (48 cells, 40 clones); however, these T cells had similarly diverse TCR repertoires capable of recognizing multiple components of the virus (Fig. 4C). Notably, both ICU adults had clonally expanded SARS-CoV-2-annotated $\mathrm{CD}^{+} \mathrm{T}$ cells. The differences were more apparent in the $\mathrm{CD} 8^{+} \mathrm{T}$ cell compartment where children had more SARS-CoV-2-specific $\mathrm{CD}^{+} \mathrm{T}$ cells (mean of 75 cells, 66 clones in children compared to mean of 41 clones in non-ICU adults and 
12.5 in ICU adults) and these included a small number of expanded clonotypes in four of six children

(Fig. 4D). SARS-CoV-2-annotated $\mathrm{CD}^{+} \mathrm{T}$ cell clonal expansions were more marked in several adults, particularly ICU adults where the SARS-CoV-2 annotated repertoire in both acute and convalescent phase was dominated by a few clones.

We aggregated the SARS-CoV-2-annotated $\mathrm{CD}^{+} \mathrm{T}$ cells and noted that this compartment in children comprised predominantly naïve cell clusters (naïve, $\mathrm{CD} 40 \mathrm{LG}^{+}$, stressed, transcriptionally active and interferon-activated) at both the acute and convalescent timepoints (Fig. 4E). Adults, whose repertoire was dominated by virus-specific TEM, early memory and Tregs, had significantly less naïve and more antigen-experienced SARS-CoV-2-annotated $\mathrm{CD}^{+} \mathrm{T}$ cells compared to children (351 naïve, 102 antigen-experienced in children; 133 naïve, 64 antigen-experienced in non-ICU; 25 naïve, 71 antigen-experienced in ICU adults; $p<0.001$, Chi-square). These differences were more pronounced in the $\mathrm{CD}^{+} \mathrm{T}$ cell repertoire where children had more naïve cells than adults (329 naïve, 123 antigen-experienced in children; 118 naïve, 90 antigen-experienced in non-ICU; 4 naïve, 134 antigen-experienced in ICU adults; p $<0.001$, Chi-square) (Fig. 4F).

We also analyzed for the expression of TCRs directed against conserved early components of the SARS-CoV-2 replication-transcription complex (RTC) encoded within ORF1ab, including RNApolymerase cofactor non-structural protein 7 (NSP7), RNA-dependent RNA polymerase (NSP12) and RNA helicase (NSP13), that have been proposed to cross-react with hCoV (Swadling et al., 2021). Children had more RTC-specific T cells and these were predominantly naïve compared to non-ICU adults where they were almost exclusively antigen-experienced and ICU adults where they were a mix of naïve and experienced T cells (Fig. 4G). Interestingly, the transition from acute to convalescence was associated with attrition of RTC-specific antigen-experienced T cells in both children and adults. Taken together, these data reveal differences in the SARS-CoV-2-specific T cell compartment in children and adults that may reflect prior antigen exposure to cross-reactive hCoV and virus-induced changes to $\mathrm{T}$ cell composition and repertoire.

\section{Annotation and tracking of $T$ cell clonotypes in children and adults}

306 Analysis of the annotated clonotypes revealed that the majority of T cells were unique and only could be detected at either the acute or convalescent timepoints, but rarely both (Fig. 5A). T cell clonotypes that could be tracked longitudinally were more prevalent in the $\mathrm{CD}^{+} \mathrm{T}$ cell compartment in ICU adults. The $\mathrm{CD}^{+}$compartment was almost entirely comprised of unique clonotypes (single cells)

310 with a higher proportion of clonotypes being expanded ( $>1$ cell) within the $\mathrm{CD} 8^{+} \mathrm{T}$ cell compartment

311 for both the children and adults (Fig. 5B). Notably, adults had a higher frequency of expanded 
312 clonotypes compared to children, especially the ICU adults. Clonally expanded T cells detected at

313 both acute and convalescent timepoints were considered longitudinal clones.

315 A small number of $\mathrm{CD}^{+}$and $\mathrm{CD}^{+} \mathrm{T}$ cell clones were detected in both the acute and convalescent 316 phase in both children and adults making it possible to track their trajectories (Fig. 5C). The CD4 ${ }^{+} \mathrm{T}$ 317 cells tended to be antigen-experienced and unique at the acute timepoint. In contrast, the $\mathrm{CD}^{+} \mathrm{T}$ cells 318 were almost exclusively made up of antigen-experienced cells which were a mix of both unique and 319 clonally expanded cells in the acute phase. We tracked the transcriptional state of these longitudinal 320 clones to determine if they had undergone cellular differentiation and found that most clonotypes 321 were stable with few transitions from one T cell state to another (Fig. 5C). We identified 27 out of $32238,051(0.07 \%)$ naïve $\mathrm{CD}^{+} \mathrm{T}$ cells in children that transitioned to TEM and 97 out of $15,022(0.65 \%)$ 323 in non-ICU adults that transitioned to early memory T cells ( $\mathrm{p}<0.0001$, Fisher's exact test) (Fig. 5D). 324 Interestingly, child TEM and non-ICU adult $\mathrm{CD}^{+}$early memory $\mathrm{T}$ cells all originated from the novel 325 interferon-activated naïve $\mathrm{CD}^{+} \mathrm{T}$ cell pool. These cells were not annotated as SARS-CoV-2-specific 326 in the ImmuneCODE and VDJdb databases but, given their differentiation trajectory, may represent 327 clonotypes responding to the virus. No transitions from naïve to memory were identified in the CD8 ${ }^{+}$ $328 \mathrm{~T}$ cell clonotypes. Thus, naïve $\mathrm{CD}^{+} \mathrm{T}$ cells were significantly more likely to differentiate into memory $\mathrm{T}$ cells in adults than children with the same disease severity.

\section{Longitudinal tracking of SARS-CoV-2-annotated $T$ cells in children and adults}

332 We next examined the trajectories of SARS-CoV-2-annotated T cells. This revealed that in children 333 they were rarely clonally expanded, consisting of $1.39 \%$ of acute and $1.30 \%$ of convalescent $\mathrm{CD}^{+} \mathrm{T}$ clones, and $6.52 \%$, of acute and $4.19 \%$ of convalescent $\mathrm{CD}^{+} \mathrm{T}$ clones (Fig. 5E). Even among the non-ICU adult $\mathrm{CD}^{+}$compartment, clonal expansions of the SARS-CoV-2-annotated cells were rare (acute 7.87\%, convalescent 7.32\%) (Fig. 5E). The most evidence for SARS-CoV-2-specific T cell clonal expansion was in the ICU adult $\mathrm{CD}^{+}$compartment where $50 \%$ and $57 \%$ of the SARS-CoV2-annotated clonotypes were expanded at both sampling timepoints, respectively. Only 6 or 7 clonotypes, equating to $0.71 \%$ and $1.95 \%$ in kids and non-ICU adults, respectively, were found at

340 both timepoints (Fig. 5F). Of the expanded clones, $25 \%$ of the $\mathrm{CD} 8^{+}$clonotypes from the ICU adults 341 were longitudinal cloned present at both timepoints. For ICU adult A13, the 7 days between sampling may make repeated detection on the same clonotypes more likely, but this was also observed for ICU adult A14, who was sampled 149 days apart. These CD8 ${ }^{+}$SARS-CoV-2-specific T cells showed no

344 evidence of phenotypic differentiation (Fig. 5F). Taken together, these data suggest that children have 345 a large pool of diverse, polyclonal naïve virus-specific T cells that largely remain intact, whereas the 
adult repertoire include clonally expanded memory $\mathrm{T}$ cells that undergo activation and attrition, possibly via terminal differentiation.

\section{Functional state of SARS-CoV-2-specific $\mathrm{T}$ cells in children and adults}

The TCR annotations enabled further analysis of the interferon response gene signature that was differentially expressed at the global level between T cells from children and non-ICU adults (Fig. 3E). The interferon response gene signature was enriched in SARS-CoV-2-specific T cells and we were able to detect high scores in cells, such as subpopulations of $\mathrm{CD} 8^{+} \mathrm{T}$ cells, that were not evident at the global level (Fig. 6A). Interferon-activated naive $\mathrm{CD}^{+} \mathrm{T}$ cells and $\mathrm{CD} 20^{+} \mathrm{CD}^{+} \mathrm{T}$ cells from non-ICU adults had the highest interferon response scores. We were also able to annotate a number of TCR specificities against cytomegalovirus (CMV), Epstein-Barr virus (EBV) and influenza. There were sufficient numbers of CMV-specific T cells (138 CD4 ${ }^{+}$and $271 \mathrm{CD}^{+}$clones), but not enough EBV- or influenza-specific T cells, to enable their analysis. No CMV-specific T cell clones were detected in ICU adults. Interestingly, we detected interferon-response gene activation during the acute phase in a small number of CMV-specific cytotoxic KLRB1 ${ }^{+}$cytotoxic and GZMK ${ }^{+}$TEM (Fig. 6A). This suggests that there may be bystander $\mathrm{T}$ cell activation, particularly in acute non-ICU adults where the score was higher.

To further investigate the functional state of SARS-CoV-2-specific $\mathrm{T}$ cells, we generated a cytotoxicity gene signature (Table S4). Globally, this signature was strongest in $\mathrm{CD}^{+}$cytotoxic $\mathrm{T}$ cells, and stronger in adults, particularly ICU adults, than children, and absent in the $\mathrm{CD}^{+}$naïve $\mathrm{T}$ cell and $\mathrm{CD}^{+} \mathrm{T}$ cell populations (Fig. 6B). Interestingly, $\mathrm{KLRB}^{+}$cytotoxic $\mathrm{T}$ cells, despite their expression of cytotoxicity genes such as GZMK, GZMA, NKG7, CST7 and GNLY (Table S2), did not have a high cytotoxicity score. $\mathrm{CD}^{+} \mathrm{GZMK}^{+} \mathrm{TEM}$ cells in adults expressed a higher cytotoxicity score than children. Overall, there was evidence for increased cytotoxicity in adults compared to children, and this was most noticeable during acute infection. We also detected upregulation of cytotoxic genes in CMV-specific effector cells in the acute stage in children and in both stages in non-ICU adults.

We next generated a $\mathrm{T}$ cell exhaustion signature (Table S4). $\mathrm{T}$ cell exhaustion scores were significantly higher in $\mathrm{CD}^{+}$than $\mathrm{CD}^{+} \mathrm{T}$ cells where it was predominantly expressed by $\mathrm{CD} 4^{+}$ interferon-activated naïve T cells (Fig. 6C). Expression was highest in ICU adults, followed by nonICU adults and then children. Expression was higher during acute infection than in convalescence. In the $\mathrm{CD} 8^{+} \mathrm{T}$ cell compartment there was evidence for exhaustion of the $\mathrm{GZMK}^{+} \mathrm{TEM}$ exhausted memory precursors and cytotoxic T cell subpopulations, particularly the KLRB1 ${ }^{+}$cytotoxic $\mathrm{T}$ cells. 
381 Exhaustion scores were higher during acute infection than convalescence and higher in non-ICU

382 adults than children. This pattern was also evident in the SARS-CoV-2- and CMV-annotated T cells, 383 but the smaller number of cells in these groups meant that several cell types were missing. Taken 384 together, these data suggest that SARS-CoV-2-specific T cells in children are less activated, less cytotoxic and less exhausted than their adult counterparts.

\section{Memory $T$ cell responses to SARS-CoV-2 in children and adults}

388 To determine the functional consequences of these age-specific differences in $\mathrm{T}$ cell composition and 389 transcriptional state we performed in vitro stimulation with recombinant RBD and S protein to detect antigen-induced upregulation of CD25 and CD134 (OX40) in CD4 ${ }^{+}$T cells (Zaunders et al., 2009).

391 This assay specifically detects $\mathrm{CD} 45 \mathrm{RO}^{+}$memory $\mathrm{T}$ cells that are activated after secondary stimulation and not naïve $\mathrm{T}$ cells that have not encountered antigen before (Phetsouphanh et al., 2014). This analysis showed that during acute infection, children had variable responses to RBD, which did not significantly change upon recovery (Fig. 7A). In contrast, paired samples from nonICU adults showed a consistent increase in the memory $\mathrm{CD}^{+} \mathrm{T}$ cell response to RBD in all patients. A similar pattern was observed in the $\mathrm{CD}^{+} \mathrm{T}$ cell response to $\mathrm{S}$ protein, with no significant increase in children in contrast to the uniform increase in paired samples from all non-ICU adults (Fig. 7B). These differences were reflected in the $\mathrm{T}$ cell proliferation assay, which showed significant increase in proliferative responses to RBD (Fig. 7C) and S protein (Fig. 7D) in adults but not children. There was a moderately positive correlation between the acquisition of memory $\mathrm{CD}^{+} \mathrm{T}$ cell responses in

401 the convalescent phase and age to RBD (Fig. 7E) and S antigen (Fig. 7F). There was also a 402 moderately positive correlation between responses to RBD and the number of SARS-CoV-2-specific 403 memory $\mathrm{CD}^{+} \mathrm{T}$ cells $($ Fig. 7G) and a trend towards correlation for responses to S protein $(\mathbf{F i g}$. 7H). 404 These data are consistent with the single cell transcriptomic and TCR repertoire analysis and show 405 that natural infection with SARS-CoV-2 induces $\mathrm{T}$ cell memory in adults more efficiently than in 406 children.

\section{DISCUSSION}

409 The immune response to SARS-CoV-2 and the immunopathogenesis of severe life-threatening 410 COVID-19 has been the focus of intense investigation in the two years since the first cluster of 411 pneumonia cases were reported in Wuhan, China on the $31^{\text {st }}$ of December, 2019. Important insights 412 have derived from the application of innovative single cell technologies and tissue sampling 413 techniques to deconvolute the local and systemic immune response (Tian et al., 2021). While initial 414 studies have examined adults across the disease severity spectrum, it is only recently that efforts have 415 been directed more towards understanding the immune response of children exposed to SARS-CoV- 
2. These studies have contributed to a detailed picture in which children are able to rapidly eliminate the virus due to their higher steady state expression of interferon genes and pre-activated innate immune system, especially in the upper respiratory tract (Loske et al., 2021; Yoshida et al., 2021). Similar local innate immune defense mechanisms may operate to protect children from SARS and Middle Eastern Respiratory Syndrome (MERS) to which they are also less susceptible (Rajapakse and Dixit, 2021; Zimmermann and Curtis, 2020). However, this innate resistance to SARS-CoV-2 infection may come at a cost and it is still unclear how the rapid clearance of viral antigens impacts on the adaptive immune response and the generation of immunological memory in children. This is particularly relevant as there is emerging public health concerns over the relative merits and risks of infection- versus vaccine-induced immunity in children. Here, we have concentrated on the systemic immune response in children and adults with the same mild/asymptomatic disease and tracked responses during acute infection and in the convalescent recovery phase to ascertain the factors that may contribute to age-specific differences in COVID-19 severity and its consequences for SARSCoV-2 immunity. Our longitudinal study avoids any confounding effects from studying heterogeneous patients suffering from varying disease severity.

Our multimodal analysis of the acute and convalescent immune response revealed that COVID-19 leaves a deeper immunological footprint in the adaptive immune system in adults than children. While both children and adults make similar antibody responses against $\mathrm{S}$ protein, adults had more circulating activated CD38 ${ }^{+} \mathrm{HLA}_{-} \mathrm{DR}^{+} \mathrm{T}$ cells. CD38 and HLA-DR are classical markers of viral infection which may also be induced by bystander activation (Jia et al., 2021; Kim and Shin, 2019) and trogocytosis (Jia et al., 2021). The ICU adults with the highest frequency of activated CD38 $8^{+}$ HLA-DR ${ }^{+}$T cells also had elevated serum IL-6 levels. Deconvolution of the circulating immune compartment by high dimensional flow cytometry and single cell RNA sequencing revealed agespecific differences in cellular composition of the NK, B and T cell compartments. However, we also detected widespread upregulation of interferon-induced genes in both the innate (monocytes and NK cells) and adaptive compartment $\left(\mathrm{B}, \mathrm{CD} 4^{+}\right.$and $\mathrm{CD} 8^{+} \mathrm{T}$ cells) in adults during acute infection, but this signature was largely limited to the innate compartment in children. This may reflect differences in timing with early production of interferon in children and late interferon production in adults. The importance of interferons in antiviral immunity and resistance to SARS-CoV-2 infection has been well recognized (Lee and Shin, 2020). What was surprising was the fact that interferon gene signatures were largely restricted to the innate immune compartment, suggesting that SARS-CoV-2 infection left only a small immunological footprint in the circulating B and T cells in children. These data are consistent with evidence for reduced breadth of SARS-CoV-2 antibodies in children (Weisberg et al., 2021). 
452 Our analysis also revealed novel subpopulations of naïve T cells, including interferon-activated naïve $453 \mathrm{CD}^{+}$and $\mathrm{CD}^{+} \mathrm{T}$ cells which were expanded during acute infection and declined in the convalescent 454 recovery phase in children, but which nevertheless were also detectable in healthy adults. 455 Interestingly, naïve $\mathrm{T}$ cells exposed to interferon or interferon-induced cytokines, such as IL-15, 456 exhibit signs of activation but do not undergo cell proliferation (Tough et al., 1999). In this regard, it 457 is notable that persistent secretion of type I and type III interferon and activated naïve T cells have 458 been reported in patients with post-COVID-19 syndrome (Phetsouphanh et al., 2022) and it will be 459 interesting to determine if such patients have persistent expansion of interferon-activated naïve CD4 ${ }^{+}$ 460 and $\mathrm{CD}^{+} \mathrm{T}$ cells. Interferon activation of naïve $\mathrm{CD} 8^{+} \mathrm{T}$ cells have been postulated to enhance their 461 homing, survival, differentiation, antiviral and antibacterial effector functions (Jergovic et al., 2021; 462 Urban et al., 2016). Importantly, clonal tracking revealed that interferon-activated $\mathrm{CD} 4^{+} \mathrm{T}$ cells were 463 the precursors of TEM in children and $\mathrm{CD}^{+}$early memory $\mathrm{T}$ cells in adults. These transitioning 464 expanded $\mathrm{T}$ cell clones may represent unannotated SARS-CoV-2-specific $\mathrm{T}$ cells. Interferon465 activated naïve $T$ cells are a novel cell population and add to the growing recognition from single cell 466 analyses that seemingly homogeneous cell populations, in this case the naïve $\mathrm{T}$ cell pool, may be more heterogeneous than previously recognized (Nguyen et al., 2018; Tian et al., 2021). Furthermore, this suggests that traditional nomenclature based on cell surface markers may be inadequate.

We simultaneously sequenced the transcriptome and TCR repertoire of circulating $\mathrm{T}$ cells to characterize the SARS-CoV-2-reactive T cell compartment and the impact of COVID-19 on T cell fate and antiviral memory. Children had more diverse TCR repertoires than adults, consistent with their immunological age and previous reports (Naylor et al., 2005; Yoshida et al., 2021). Interestingly, the SARS-CoV-2-specific T cell compartment in children consisted predominantly of naïve T cells with a diverse repertoire capable of recognizing multiple $\mathrm{T}$ cell epitopes, including $\mathrm{T}$ cells that recognize components of the RTC. RTC-specific memory T cells have recently been proposed to cross-react with hCoV and mediate immunity during abortive SARS-CoV-2 infection in adult health care workers (Swadling et al., 2021). These data suggest that cross-reactive antigen-specific T cells generated by VDJ recombination during ontogeny may still be naïve and not yet selected by antigen 480 experience into the memory pool, particularly in young children who have not been repeatedly 481 exposed to cross-reactive hCoV (Gorse et al., 2020; Pierce et al., 2020; To et al., 2020). In contrast, adults harbored fewer SARS-CoV-2-specific T cells and these included a large number of clonally expanded memory $\mathrm{T}$ cells, including to the RTC, that may have been selected by prior infection with $484 \mathrm{hCoV}$. Such pre-existing cross-reactive $\mathrm{T}$ cell memory has been implicated as a risk factor for severe COVID-19 in the elderly (Bacher et al., 2020). On the other hand, recent infection with endemic 
hCoV have also been associated with less severe COVID-19, possibly by "back-boosting" preexisting immunity (Sagar et al., 2021).

In addition to the differences in cellular composition, we also detected differences in the transcriptional state of the $\mathrm{T}$ cells in children and adults. It has been reported that patients admitted to ICU with severe COVID-19 may have impaired cytotoxicity compared to non-ICU patients as measured by reduced secretion of IL-2 and interferon- $\gamma$ following in vitro polyclonal stimulation (Mazzoni et al., 2020). However, our analysis showed that ICU adults had enhanced cytotoxicity scores (particularly in SARS-CoV-2-specific $\mathrm{CD}^{+} \mathrm{T}$ cells) compared to non-ICU adults, whereas children had the lowest cytotoxicity scores. This cytotoxicity score encompasses 67 genes that includes, but are not limited to, IL-2 and interferon- $\gamma$. Increased T cell cytotoxicity in severe COVID19 has also been reported by other investigators (Meckiff et al., 2020). Intriguingly, it has also been reported that severely ill COVID-19 patients show features of impaired $\mathrm{T}$ cell exhaustion from the single cell RNA sequencing of expanded T cells generated by in vitro stimulation with SARS-CoV2 peptide pools (Kusnadi et al., 2021). In contrast, our transcriptomic analysis of unstimulated T cells shows a clear hierarchy of exhaustion with children having the least exhausted $\mathrm{CD} 8^{+} \mathrm{T}$ cells followed by non-ICU and then ICU adults. This is consistent with a number of studies showing evidence of T cell exhaustion in patients with severe COVID-19 (De Biasi et al., 2020; Diao et al., 2020; Laing et al., 2020; Zheng et al., 2020a; Zheng et al., 2020b), although it may be difficult to distinguish exhausted from activated cell states (Rha and Shin, 2021; Wherry and Kurachi, 2015). The exhaustion in both non-ICU and ICU adult T cells was accompanied by mitochondrial dysfunction and increased expression of OXPHOS genes, particularly in the two ICU adults. Metabolic dysregulation in patients with severe COVID-19 has been previously described (Siska et al., 2021; Thompson et al., 2021). Taken together, these data suggest that SARS-CoV-2-specific T cells from adult were more activated and terminally differentiated than children despite having the same disease severity.

One puzzling aspect of our data is the fact that many naïve SARS-CoV-2-specific T cells remained suggesting that they either failed to be activated or were transiently activated and returned to a naïve state. When naïve longitudinal clones were detected we only observed recruitment into the memory pool of small numbers of interferon-activated naïve T cells, and this was largely in non-ICU adults. This may reflect sampling differences between timepoints and also biological differences between children and adults. In adults, there is evidence for activation, cytotoxicity and exhaustion of circulating SARS-CoV-2-specific T cells. Under these circumstances, it is possible that hCoV crossreactive memory and cytotoxic $\mathrm{T}$ cells are preferentially recruited at the expense of naïve $\mathrm{T}$ cells into the SARS-CoV-2 response where they undergo terminal differentiation leading to clonal attrition and 
contraction of the SARS-CoV-2-specific memory and effector T cell pool in convalescence. This exclusion of adult naïve $\mathrm{T}$ cells from the response by pre-existing cross-reactive memory $\mathrm{T}$ cells is consistent with T cell original antigenic sin (Klenerman and Zinkernagel, 1998). Such imprinting may bias $\mathrm{T}$ cell responses and promote the immune escape of SARS-CoV-2 and its variants. The description of pre-existing RTC-specific T cells that expand in adult health care workers with abortive SARS-CoV-2 infection (Swadling et al., 2021) argues against this notion. However, we found antigen-experienced RTC-specific T cells decreased in number in both adults and children, consistent with their clonal attrition. In children, we have shown that, apart from the interferon-activated naïve $\mathrm{T}$ cells, there is little evidence for activation of circulating $\mathrm{T}$ cells. Therefore, it is possible that naïve SARS-CoV-2-specific T cells are sub-optimally activated in children due to the rapid clearance of viral antigens (Loske et al., 2021; Tosif et al., 2020; Yoshida et al., 2021). Rapid viral clearance may also shut down the secretion of interferon and interferon-induced IL-15, cytokines that have been shown to be needed for the generation of $\mathrm{CD}^{+}$memory $\mathrm{T}$ cells (Kolumam et al., 2005; Schluns and Lefrancois, 2003). This has important implications for the development of $\mathrm{T}$ cell memory and the protection afforded by infection-induced immunity in children.

Longitudinal analysis detected the generation of robust $\mathrm{CD}^{+} \mathrm{T}$ cell memory responses to RBD and $\mathrm{S}$ protein in adults but not children by the OX40 assay, which detects memory and not naïve $\mathrm{CD}^{+} \mathrm{T}$ cell responses (Phetsouphanh et al., 2014; Zaunders et al., 2009). In children, this result is consistent with the single cell transcriptomic and TCR data showing little evidence for activation of circulating SARS-CoV-2-specific T cells and recruitment of naïve T cells into the memory pool. Adults also did not show evidence of de novo naïve $\mathrm{T}$ activation or recruitment but, in contrast to the children, had an expanded SARS-CoV-2-specific memory $\mathrm{T}$ cell pool. We noted that OX40 responses were positively correlated with age and the number of SARS-CoV-2-specific memory $\mathrm{CD}^{+} \mathrm{T}$ cells. Interestingly, single cell analysis of in vitro stimulated PBMCs suggest that severe COVID-19 is associated with increased cytotoxic $\mathrm{CD}^{+}$and decreased regulatory $\mathrm{T}$ cell activity (Meckiff et al., 2020). We note that early memory $\mathrm{T}$ cells and Tregs dominated the SARS-CoV-2-specific $\mathrm{CD}^{+}{ }^{+} \mathrm{T}$ cell compartment in the ICU adults. There was also more evidence of acute systemic T cell activation, cytotoxicity and exhaustion in both SARS-CoV-2-specific and non-specific adult $\mathrm{T}$ cells which declined in convalescence. Therefore, the development of RBD and S protein memory $\mathrm{T}$ cell responses in adults may not only be due to the emergence of new memory $\mathrm{T}$ cells from interferonactivated naïve $\mathrm{T}$ cells but also recovery of pre-existing memory $\mathrm{T}$ cells from exhaustion or active suppression by regulatory $\mathrm{T}$ cells. 
Several studies from Hong Kong, Australia and the United States have shown impaired humoral and cellular immune responses in children exposed to SARS-CoV-2 (Cohen et al., 2021; Toh et al., 2021; Tosif et al., 2020; Weisberg et al., 2021). This agrees with our data showing impaired generation of $\mathrm{T}$ cell memory responses in children compared to adults. It is possible that the rapid efficient elimination of virus by the innate immune system reduces the antigen availability and prolonged cytokine exposure needed to generate long-lived cellular immunity. Under this scenario, since responses are short-lived, children are dependent on their primed innate immune system for continuing protection from reinfection. These data collectively contradict a recent study showing that children may actually generate more robust adaptive immune responses to SARS-CoV-2 than adults (Dowell et al., 2022). In a large cohort of convalescent primary school children and their teachers from England, it was shown that children make higher titres of cross-reactive antibodies and $\mathrm{T}$ cell memory responses than adults. However, this involved a heterogeneous study group with an uneven mix of male and female patients who are not hospitalized but may otherwise suffer from varying degrees of disease severity. Another point of difference is that our study examines the response of a naïve patient group to the second wave of COVID-19 in Sydney which occurred after a period of a time when there was no SARS-CoV-2 cases in the community. The study from England began recruiting after the lockdown was lifted in June, 2020 in the setting of widespread community transmission and may include children and adults who have been multiply exposed to SARS-CoV-2.

A critical question arising from all these studies is the risk of reinfection following COVID-19 in children. Our data supports other studies that would suggest that potent innate immunity undermines the adaptive immune response. If correct this suggests that vaccination, for example with of the BNT162b2 Covid-19 vaccine (Walter et al., 2021), will be required to bypass this immune bottleneck in the upper airway in children and allow them to generate long-lasting immunity.

\section{Limitations of the study and future directions}

581 There are several limitations to our study. The sample size of our cohort is relatively small and this 582 reduces the confidence in our conclusions. However, this is mitigated by the longitudinal study design 583 and the fact that we have focused on the systemic immune response in patients with the same 584 asymptomatic/mild disease severity from the same households. We longitudinally followed patients from the acute stage to convalescence, and complemented our cohort with an additional two patients with severe COVID-19. We also analyzed 433,301 single cells directly ex vivo, making it one of the larger single cell datasets to be made available. Another limitation of our study is the short study period and it will be interesting to see the impact of immunity on intercurrent hCoV and SARS-CoV- 
590 longitudinal study of homogeneous patient groups with the same disease severity will be needed to

591 determine the relative merits and risks of infection- vs vaccine-induced immunity against SARS-

$592 \mathrm{CoV}-2$. Due to technical reasons and the volume of blood sample available from children, we were

593 only able to test memory $\mathrm{CD}^{+} \mathrm{T}$ cell responses to $\mathrm{RBD}$ and $\mathrm{S}$ protein. In addition, the identification

594 of SARS-CoV-2-specific T cells in our study was dependent on the annotation of their TCR in

595 ImmuneCODE and VDJdb databases, which are almost certainly incomplete. Another limitation of

596 our study is the absence of pre-exposure blood samples and viral loads to determine the kinetics of

597 viral clearance, interferon response and baseline cross-reactive immunity to hCoV. Future studies

598 involving more innovative technologies with smaller sample requirements, including nasal sampling

599 of local immune responses, may provide a more complete picture of the dynamic clonal landscape of

600 both local and systemic T cell responses to SARS-CoV-2 and hCOV.

\section{Acknowledgments}

603 We thank the patients and their families. We thank Miles Davenport, Tony Basten and Robert Brink 604 for critical discussions and comments on the manuscript. We thank Eric Lim, Hira Saeed and staff in the Garvan-Weizmann Centre for Cellular Genomics for technical support. Drawings were created

\section{Funding}

609 P.I.C. and T.G.P. are supported by Mrs. Janice Gibson and the Ernest Heine Family Foundation. 610 T.G.P., P.N.P. and J.E.P. are supported by National Health and Medical Research Council (NHMRC) 611 Fellowships APP1155678, APP1145817 and APP1107599, respectively. W.H.K. is supported by the 612 UNSW Cellular Genomics Futures Institute. RD is supported by a UNSW Scientia PhD Scholarship. 613 WK is supported by a Research Training Program scholarship. This work is supported by the Garvan 614 Institute COVID Catalytic Grant, UNSW COVID-19 Rapid Response Research Initiative, National 615 Institutes of Health Centers of Excellence for Influenza Research and Response (CEIRR) COVID616 19, Snow Medical Foundation BEAT COVID-19 and Griffith University funding.

\section{Author contributions}

619 P.N.B. is the coordinating principal investigator for clinical site. R.N., P.S.H., P.N.B. and T.G.P. conceived and designed the study. R.N., P.S.H., P.N.B., A.H.-J., A.B., B.T., N.W. and D.C. recruited patients and collected patient data. D.R.C. leads the biospecimen research services. L.Z., A.Y., C.L.L., T.V. and R.B. collected and processed patient samples. R.B. managed the project. W.H.K. and T.G.P. designed experiments. W.H.K. performed single cell transcriptome and repertoire sequencing. M.S. performed bulk TCR sequencing. W.H.K., K.J., J.A.-H., S.Y., J.E.P., W.K. and 
625 T.G.P. analyzed the sequencing data. K.J. analyzed the TCR repertoire. C.P. and J.J.Z. performed in 626 vitro T cell stimulation. S.R.-D. and E.K.D. performed and analyzed the flow cytometry and cytokine 627 bead array. F.L., V.M., F.X.Z.L and F.B. measured anti-S antibodies. R.R. and D.C. generated the 628 recombinant RBD and S proteins. P.I.C., A.K.D., C.G.G., J.E.P., R.N., P.S.H., P.N.B. and T.G.P. 629 provided supervision. W.H.K., K.J., J.D.S., P.I.C., A.K.D., R.N., P.S.H., E.K.D., P.N.B. and T.G.P. 630 wrote the manuscript.

\section{Declaration of interests}

633 The authors declare no competing financial interests. 


\section{References}

636 Anderson, E.M., Goodwin, E.C., Verma, A., Arevalo, C.P., Bolton, M.J., Weirick, M.E., Gouma, S., McAllister, C.M., Christensen, S.R., Weaver, J., et al. (2021). Seasonal human coronavirus antibodies are boosted upon SARS-CoV-2 infection but not associated with protection. Cell 184, 1858-1864 e1810.

Aydillo, T., Rombauts, A., Stadlbauer, D., Aslam, S., Abelenda-Alonso, G., Escalera, A., Amanat,

F., Jiang, K., Krammer, F., Carratala, J., and Garcia-Sastre, A. (2021). Immunological imprinting of the antibody response in COVID-19 patients. Nature communications 12, 3781.

Bacher, P., Rosati, E., Esser, D., Martini, G.R., Saggau, C., Schiminsky, E., Dargvainiene, J.,

Schroder, I., Wieters, I., Khodamoradi, Y., et al. (2020). Low-Avidity CD4(+) T Cell Responses to

SARS-CoV-2 in Unexposed Individuals and Humans with Severe COVID-19. Immunity 53, 1258$1271 \mathrm{e} 1255$.

Bagaev, D.V., Vroomans, R.M.A., Samir, J., Stervbo, U., Rius, C., Dolton, G., Greenshields-Watson,

A., Attaf, M., Egorov, E.S., Zvyagin, I.V., et al. (2020). VDJdb in 2019: database extension, new analysis infrastructure and a T-cell receptor motif compendium. Nucleic Acids Res 48, D1057D1062.

651 Bartsch, Y.C., Wang, C., Zohar, T., Fischinger, S., Atyeo, C., Burke, J.S., Kang, J., Edlow, A.G., Fasano, A., Baden, L.R., et al. (2021). Humoral signatures of protective and pathological SARSCoV-2 infection in children. Nature medicine 27, 454-462.

Billerbeck, E., Kang, Y.H., Walker, L., Lockstone, H., Grafmueller, S., Fleming, V., Flint, J., Willberg, C.B., Bengsch, B., Seigel, B., et al. (2010). Analysis of CD161 expression on human CD8+ T cells defines a distinct functional subset with tissue-homing properties. Proceedings of the National Academy of Sciences of the United States of America 107, 3006-3011. patients with COVID-19. Nature 587, 270-274.

661 Chen, T., Wu, D., Chen, H., Yan, W., Yang, D., Chen, G., Ma, K., Xu, D., Yu, H., Wang, H., et al. 662 (2020). Clinical characteristics of 113 deceased patients with coronavirus disease 2019: retrospective 663 study. BMJ 368, m1091.

664 Cohen, C.A., Li, A.P.Y., Hachim, A., Hui, D.S.C., Kwan, M.Y.W., Tsang, O.T.Y., Chiu, S.S., Chan, 665 W.H., Yau, Y.S., Kavian, N., et al. (2021). SARS-CoV-2 specific T cell responses are lower in 666 children and increase with age and time after infection. Nature communications 12, 4678.

667 De Biasi, S., Meschiari, M., Gibellini, L., Bellinazzi, C., Borella, R., Fidanza, L., Gozzi, L., Iannone, 668 A., Lo Tartaro, D., Mattioli, M., et al. (2020). Marked T cell activation, senescence, exhaustion and 669 skewing towards TH17 in patients with COVID-19 pneumonia. Nature communications 11, 3434. 
670 Dhenni, R., and Phan, T.G. (2020). The geography of memory B cell reactivation in vaccine-induced 671 immunity and in autoimmune disease relapses. Immunological reviews 296, 62-86.

672 Diao, B., Wang, C., Tan, Y., Chen, X., Liu, Y., Ning, L., Chen, L., Li, M., Liu, Y., Wang, G., et al. 673 (2020). Reduction and Functional Exhaustion of T Cells in Patients With Coronavirus Disease 2019 674 (COVID-19). Frontiers in immunology 11, 827.

675 Dowell, A.C., Butler, M.S., Jinks, E., Tut, G., Lancaster, T., Sylla, P., Begum, J., Bruton, R., Pearce, 676 H., Verma, K., et al. (2022). Children develop robust and sustained cross-reactive spike-specific 677 immune responses to SARS-CoV-2 infection. Nature immunology 23, 40-49.

678 Francis, T. (1960). On the doctrine of original antigenic sin. Proc Am Philos Soc 104, 572-578.

679 Galletti, G., De Simone, G., Mazza, E.M.C., Puccio, S., Mezzanotte, C., Bi, T.M., Davydov, A.N., 680 Metsger, M., Scamardella, E., Alvisi, G., et al. (2020). Two subsets of stem-like CD8(+) memory T 681 cell progenitors with distinct fate commitments in humans. Nature immunology 21, 1552-1562.

682 Gorse, G.J., Donovan, M.M., and Patel, G.B. (2020). Antibodies to coronaviruses are higher in older 683 compared with younger adults and binding antibodies are more sensitive than neutralizing antibodies 684 in identifying coronavirus-associated illnesses. J Med Virol 92, 512-517.

685 Grifoni, A., Weiskopf, D., Ramirez, S.I., Mateus, J., Dan, J.M., Moderbacher, C.R., Rawlings, S.A., 686 Sutherland, A., Premkumar, L., Jadi, R.S., et al. (2020). Targets of T Cell Responses to SARS-CoV6872 Coronavirus in Humans with COVID-19 Disease and Unexposed Individuals. Cell 181, 1489-1501 $688 \mathrm{e} 1415$.

689 Guan, W.J., Ni, Z.Y., Hu, Y., Liang, W.H., Ou, C.Q., He, J.X., Liu, L., Shan, H., Lei, C.L., Hui, 690 D.S.C., et al. (2020). Clinical Characteristics of Coronavirus Disease 2019 in China. The New 691 England journal of medicine 382, 1708-1720.

692 Huang, C., Wang, Y., Li, X., Ren, L., Zhao, J., Hu, Y., Zhang, L., Fan, G., Xu, J., Gu, X., et al. 693 (2020). Clinical features of patients infected with 2019 novel coronavirus in Wuhan, China. Lancet $694395,497-506$.

695 Jergovic, M., Coplen, C.P., Uhrlaub, J.L., Besselsen, D.G., Cheng, S., Smithey, M.J., and Nikolich696 Zugich, J. (2021). Infection-induced type I interferons critically modulate the homeostasis and 697 function of CD8(+) naive T cells. Nature communications 12, 5303.

698 Jia, X., Chua, B.Y., Loh, L., Koutsakos, M., Kedzierski, L., Olshansky, M., Heath, W.R., Chang, 699 S.Y., Xu, J., Wang, Z., and Kedzierska, K. (2021). High expression of CD38 and MHC class II on $700 \mathrm{CD} 8(+) \mathrm{T}$ cells during severe influenza disease reflects bystander activation and trogocytosis. Clin 701 Transl Immunology 10, e1336.

702 Jordan, R.E., Adab, P., and Cheng, K.K. (2020). Covid-19: risk factors for severe disease and death. 703 BMJ 368, m1198. 
Kim, T.S., and Shin, E.C. (2019). The activation of bystander CD8(+) T cells and their roles in viral infection. Exp Mol Med 51, 1-9.

Klenerman, P., and Zinkernagel, R.M. (1998). Original antigenic sin impairs cytotoxic T lymphocyte responses to viruses bearing variant epitopes. Nature 394, 482-485.

Kolumam, G.A., Thomas, S., Thompson, L.J., Sprent, J., and Murali-Krishna, K. (2005). Type I interferons act directly on CD8 $\mathrm{T}$ cells to allow clonal expansion and memory formation in response to viral infection. The Journal of experimental medicine 202, 637-650.

Kusnadi, A., Ramirez-Suastegui, C., Fajardo, V., Chee, S.J., Meckiff, B.J., Simon, H., Pelosi, E., Seumois, G., Ay, F., Vijayanand, P., and Ottensmeier, C.H. (2021). Severely ill COVID-19 patients display impaired exhaustion features in SARS-CoV-2-reactive CD8(+) T cells. Sci Immunol 6.

Laing, A.G., Lorenc, A., Del Molino Del Barrio, I., Das, A., Fish, M., Monin, L., Munoz-Ruiz, M., McKenzie, D.R., Hayday, T.S., Francos-Quijorna, I., et al. (2020). A dynamic COVID-19 immune signature includes associations with poor prognosis. Nature medicine 26, 1623-1635.

Le Bert, N., Tan, A.T., Kunasegaran, K., Tham, C.Y.L., Hafezi, M., Chia, A., Chng, M.H.Y., Lin, M., Tan, N., Linster, M., et al. (2020). SARS-CoV-2-specific T cell immunity in cases of COVID-19 and SARS, and uninfected controls. Nature 584, 457-462.

Lee, J.S., and Shin, E.C. (2020). The type I interferon response in COVID-19: implications for treatment. Nature reviews. Immunology 20, 585-586.

Loske, J., Rohmel, J., Lukassen, S., Stricker, S., Magalhaes, V.G., Liebig, J., Chua, R.L., Thurmann, L., Messingschlager, M., Seegebarth, A., et al. (2021). Pre-activated antiviral innate immunity in the upper airways controls early SARS-CoV-2 infection in children. Nat Biotechnol.

Mateus, J., Grifoni, A., Tarke, A., Sidney, J., Ramirez, S.I., Dan, J.M., Burger, Z.C., Rawlings, S.A., Smith, D.M., Phillips, E., et al. (2020). Selective and cross-reactive SARS-CoV-2 T cell epitopes in unexposed humans. Science 370, 89-94.

Mazzoni, A., Salvati, L., Maggi, L., Capone, M., Vanni, A., Spinicci, M., Mencarini, J., Caporale, R., Peruzzi, B., Antonelli, A., et al. (2020). Impaired immune cell cytotoxicity in severe COVID-19 is IL-6 dependent. The Journal of clinical investigation 130, 4694-4703.

Meckiff, B.J., Ramirez-Suastegui, C., Fajardo, V., Chee, S.J., Kusnadi, A., Simon, H., Eschweiler, S., Grifoni, A., Pelosi, E., Weiskopf, D., et al. (2020). Imbalance of Regulatory and Cytotoxic SARSCoV-2-Reactive CD4(+) T Cells in COVID-19. Cell 183, 1340-1353 e1316.

Naylor, K., Li, G., Vallejo, A.N., Lee, W.W., Koetz, K., Bryl, E., Witkowski, J., Fulbright, J., Weyand, C.M., and Goronzy, J.J. (2005). The influence of age on T cell generation and TCR diversity. J Immunol 174, 7446-7452. 
Neeland, M.R., Bannister, S., Clifford, V., Dohle, K., Mulholland, K., Sutton, P., Curtis, N., Steer, A.C., Burgner, D.P., Crawford, N.W., et al. (2021). Innate cell profiles during the acute and convalescent phase of SARS-CoV-2 infection in children. Nature communications $12,1084$.

Ng, K.W., Faulkner, N., Cornish, G.H., Rosa, A., Harvey, R., Hussain, S., Ulferts, R., Earl, C.,

Wrobel, A.G., Benton, D.J., et al. (2020). Preexisting and de novo humoral immunity to SARS-CoV2 in humans. Science 370, 1339-1343.

Nguyen, A., Khoo, W.H., Moran, I., Croucher, P.I., and Phan, T.G. (2018). Single Cell RNA Sequencing of Rare Immune Cell Populations. Frontiers in immunology 9, 1553.

Nolan, S., Vignali, M., Klinger, M., Dines, J.N., Kaplan, I.M., Svejnoha, E., Craft, T., Boland, K.,

Pesesky, M., Gittelman, R.M., et al. (2020). A large-scale database of T-cell receptor beta (TCRbeta) sequences and binding associations from natural and synthetic exposure to SARS-CoV-2. Res Sq.

O'Driscoll, M., Ribeiro Dos Santos, G., Wang, L., Cummings, D.A.T., Azman, A.S., Paireau, J.,

Fontanet, A., Cauchemez, S., and Salje, H. (2021). Age-specific mortality and immunity patterns of

SARS-CoV-2. Nature 590, 140-145.

Phetsouphanh, C., Darley, D.R., Wilson, D.B., Howe, A., Munier, C.M.L., Patel, S.K., Juno, J.A.,

Burrell, L.M., Kent, S.J., Dore, G.J., et al. (2022). Immunological dysfunction persists for 8 months following initial mild-to-moderate SARS-CoV-2 infection. Nature immunology.

Phetsouphanh, C., Xu, Y., Bailey, M., Pett, S., Zaunders, J., Seddiki, N., and Kelleher, A.D. (2014).

Ratios of effector to central memory antigen-specific CD4(+) T cells vary with antigen exposure in $\mathrm{HIV}+$ patients. Immunology and cell biology 92, 384-388.

Pierce, C.A., Preston-Hurlburt, P., Dai, Y., Aschner, C.B., Cheshenko, N., Galen, B., Garforth, S.J., infection in hospitalized pediatric and adult patients. Science translational medicine 12.

Rajapakse, N., and Dixit, D. (2021). Human and novel coronavirus infections in children: a review.

Paediatr Int Child Health 41, 36-55.

Rha, M.S., and Shin, E.C. (2021). Activation or exhaustion of CD8(+) T cells in patients with COVID-19. Cell Mol Immunol 18, 2325-2333.

Sagar, M., Reifler, K., Rossi, M., Miller, N.S., Sinha, P., White, L.F., and Mizgerd, J.P. (2021).

Recent endemic coronavirus infection is associated with less-severe COVID-19. The Journal of

767 Schluns, K.S., and Lefrancois, L. (2003). Cytokine control of memory T-cell development and survival. Nature reviews. Immunology 3, 269-279.

Selva, K.J., van de Sandt, C.E., Lemke, M.M., Lee, C.Y., Shoffner, S.K., Chua, B.Y., Davis, S.K., Nguyen, T.H.O., Rowntree, L.C., Hensen, L., et al. (2021). Systems serology detects functionally 
Siska, P.J., Decking, S.M., Babl, N., Matos, C., Bruss, C., Singer, K., Klitzke, J., Schon, M., Simeth, J., Kostler, J., et al. (2021). Metabolic imbalance of T cells in COVID-19 is hallmarked by basigin and mitigated by dexamethasone. The Journal of clinical investigation 131 .

Swadling, L., Diniz, M.O., Schmidt, N.M., Amin, O.E., Chandran, A., Shaw, E., Pade, C., Gibbons, J.M., Le Bert, N., Tan, A.T., et al. (2021). Pre-existing polymerase-specific T cells expand in abortive seronegative SARS-CoV-2. Nature.

Thompson, E.A., Cascino, K., Ordonez, A.A., Zhou, W., Vaghasia, A., Hamacher-Brady, A., Brady, N.R., Sun, I.H., Wang, R., Rosenberg, A.Z., et al. (2021). Metabolic programs define dysfunctional immune responses in severe COVID-19 patients. Cell reports 34, 108863.

Tian, Y., Carpp, L.N., Miller, H.E.R., Zager, M., Newell, E.W., and Gottardo, R. (2021). Single-cell immunology of SARS-CoV-2 infection. Nat Biotechnol.

To, K.K., Cheng, V.C., Cai, J.P., Chan, K.H., Chen, L.L., Wong, L.H., Choi, C.Y., Fong, C.H., Ng, A.C., Lu, L., et al. (2020). Seroprevalence of SARS-CoV-2 in Hong Kong and in residents evacuated from Hubei province, China: a multicohort study. Lancet Microbe 1, e111-e118.

Toh, Z.Q., Anderson, J., Mazarakis, N., Neeland, M., Higgins, R.A., Rautenbacher, K., Dohle, K., Nguyen, J., Overmars, I., Donato, C., et al. (2021). Reduced seroconversion in children compared to adults with mild COVID-19. medRxiv, 2021.2010.2017.21265121.

Tosif, S., Neeland, M.R., Sutton, P., Licciardi, P.V., Sarkar, S., Selva, K.J., Do, L.A.H., Donato, C., Quan Toh, Z., Higgins, R., et al. (2020). Immune responses to SARS-CoV-2 in three children of parents with symptomatic COVID-19. Nature communications 11, 5703.

Tough, D.F., Sun, S., Zhang, X., and Sprent, J. (1999). Stimulation of naive and memory T cells by cytokines. Immunological reviews 170, 39-47.

Urban, S.L., Berg, L.J., and Welsh, R.M. (2016). Type 1 interferon licenses naive CD8 T cells to mediate anti-viral cytotoxicity. Virology 493, 52-59.

Walter, E.B., Talaat, K.R., Sabharwal, C., Gurtman, A., Lockhart, S., Paulsen, G.C., Barnett, E.D., Munoz, F.M., Maldonado, Y., Pahud, B.A., et al. (2021). Evaluation of the BNT162b2 Covid-19 Vaccine in Children 5 to 11 Years of Age. The New England journal of medicine.

Wang, D., Hu, B., Hu, C., Zhu, F., Liu, X., Zhang, J., Wang, B., Xiang, H., Cheng, Z., Xiong, Y., et al. (2020). Clinical Characteristics of 138 Hospitalized Patients With 2019 Novel CoronavirusInfected Pneumonia in Wuhan, China. JAMA 323, 1061-1069.

Weisberg, S.P., Connors, T.J., Zhu, Y., Baldwin, M.R., Lin, W.H., Wontakal, S., Szabo, P.A., Wells, S.B., Dogra, P., Gray, J., et al. (2021). Distinct antibody responses to SARS-CoV-2 in children and adults across the COVID-19 clinical spectrum. Nature immunology 22, 25-31.

Wherry, E.J., and Kurachi, M. (2015). Molecular and cellular insights into T cell exhaustion. Nature reviews. Immunology 15, 486-499. 
Yoshida, M., Worlock, K.B., Huang, N., Lindeboom, R.G.H., Butler, C.R., Kumasaka, N., Conde,

808 C.D., Mamanova, L., Bolt, L., Richardson, L., et al. (2021). Local and systemic responses to SARS809 CoV-2 infection in children and adults. Nature.

810 Zaunders, J.J., Munier, M.L., Seddiki, N., Pett, S., Ip, S., Bailey, M., Xu, Y., Brown, K., Dyer, W.B., 811 Kim, M., et al. (2009). High levels of human antigen-specific CD4+ T cells in peripheral blood 812 revealed by stimulated coexpression of CD25 and CD134 (OX40). J Immunol 183, 2827-2836.

813 Zhang, A., Stacey, H.D., Mullarkey, C.E., and Miller, M.S. (2019). Original Antigenic Sin: How First 814 Exposure Shapes Lifelong Anti-Influenza Virus Immune Responses. J Immunol 202, 335-340.

815 Zheng, H.Y., Zhang, M., Yang, C.X., Zhang, N., Wang, X.C., Yang, X.P., Dong, X.Q., and Zheng, 816 Y.T. (2020a). Elevated exhaustion levels and reduced functional diversity of T cells in peripheral 817 blood may predict severe progression in COVID-19 patients. Cell Mol Immunol 17, 541-543.

818 Zheng, M., Gao, Y., Wang, G., Song, G., Liu, S., Sun, D., Xu, Y., and Tian, Z. (2020b). Functional 819 exhaustion of antiviral lymphocytes in COVID-19 patients. Cell Mol Immunol 17, 533-535.

820 Zhou, P., Yang, X.L., Wang, X.G., Hu, B., Zhang, L., Zhang, W., Si, H.R., Zhu, Y., Li, B., Huang, 821 C.L., et al. (2020). A pneumonia outbreak associated with a new coronavirus of probable bat origin. 822 Nature 579, 270-273.

823 Zimmermann, P., and Curtis, N. (2020). Coronavirus Infections in Children Including COVID-19: 824 An Overview of the Epidemiology, Clinical Features, Diagnosis, Treatment and Prevention Options 825 in Children. Pediatr Infect Dis J 39, 355-368.

826 Zohar, T., and Alter, G. (2020). Dissecting antibody-mediated protection against SARS-CoV-2. 827 Nature reviews. Immunology 20, 392-394. 
A

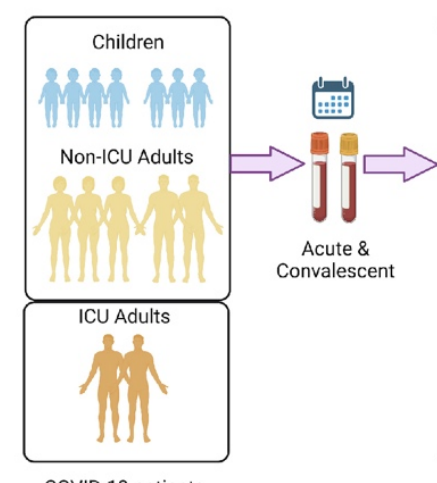

COVID-19 patients

C

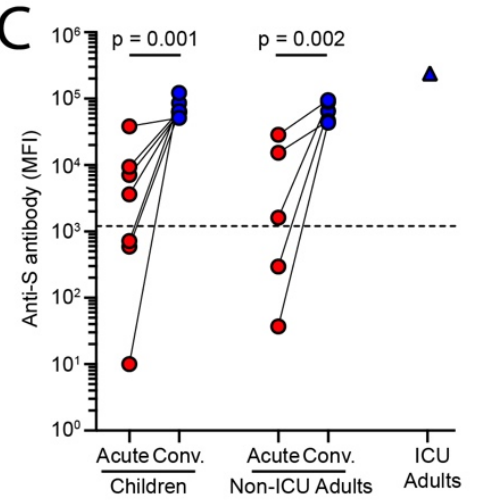

$\mathrm{E}$

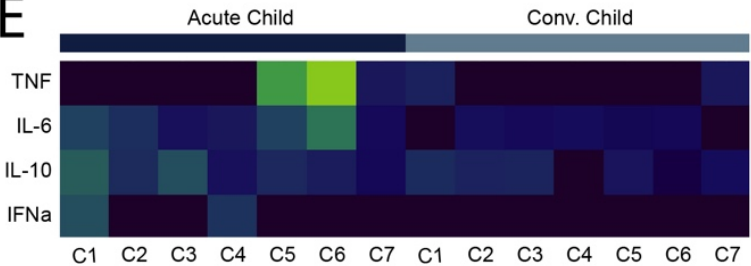

$\mathrm{F}$

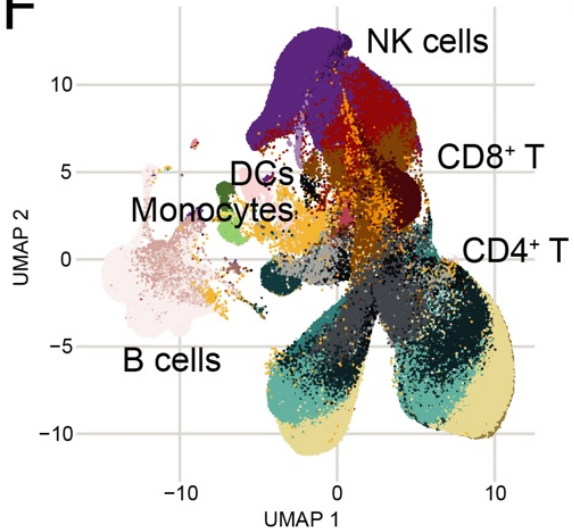

G
D

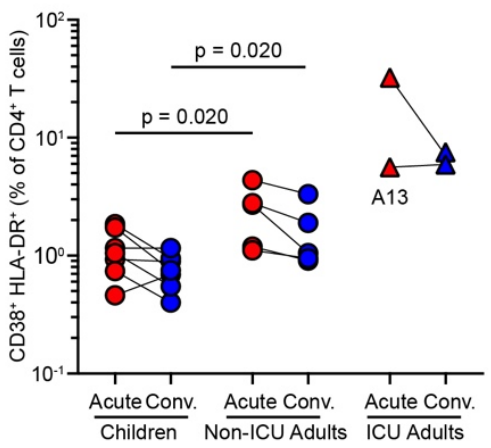

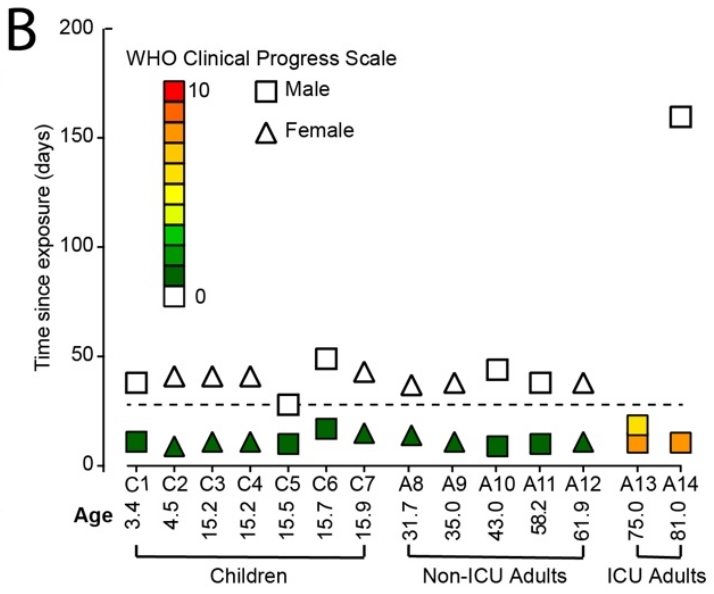

CD8 ${ }^{+} \mathrm{T}$ cells

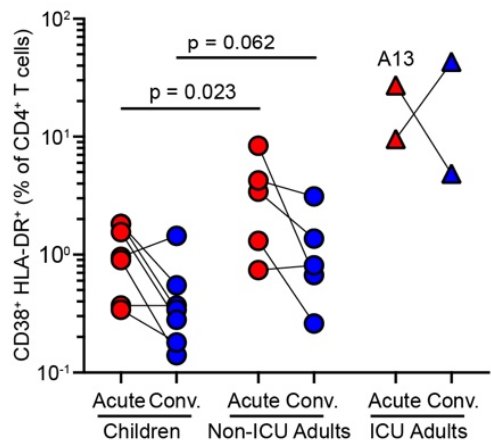

Acute Non-ICU Adult Conv. Non-ICU Adult Acute ICU Adult
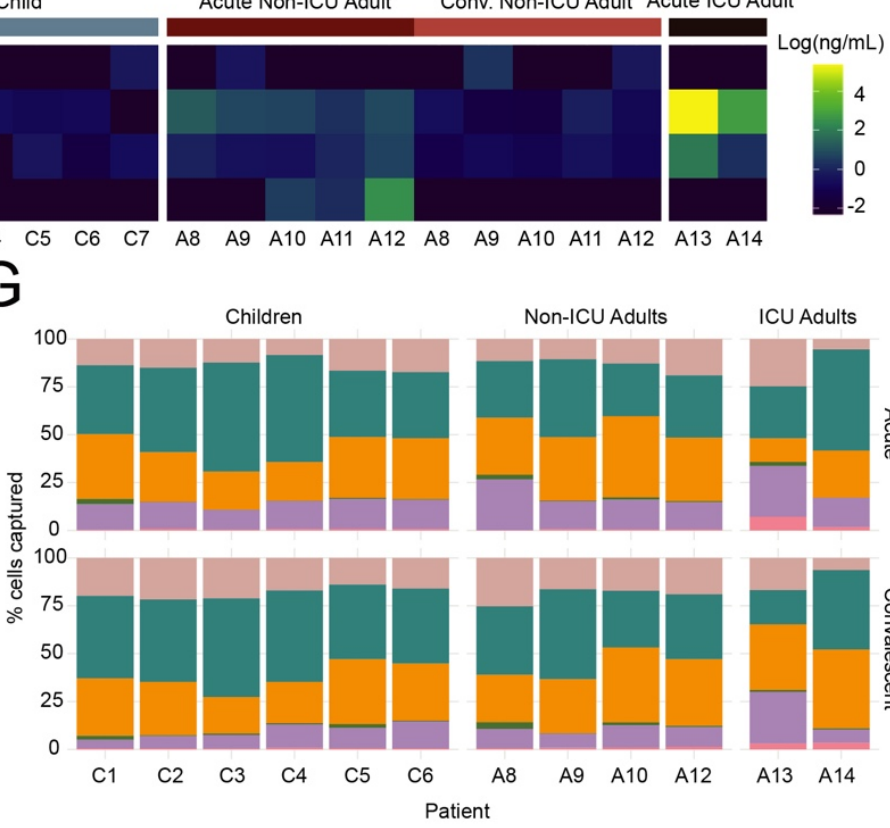

ICU Adults

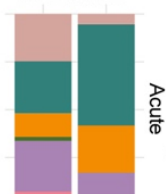

Cell populations

833 Figure 1. Multimodal analysis of children and adults with mild COVID-19.

834 (A) Study overview.

835 (B) Patient demographic and clinical severity score.

836 (C) Serum anti-S protein antibodies. 
837 (D) $\mathrm{CD} 8^{+} \mathrm{HLA}^{-\mathrm{DR}^{+}}$activated $\mathrm{CD}^{+}$(left) and $\mathrm{CD}^{+}$(right) $\mathrm{T}$ cells in children, non-ICU and ICU 838 adults during Acute and Convalescent phases.

839 (E) Heatmap of serum TNF, IL-6, IL-10 and interferon- $\alpha$.

840 (F) UMAP showing 433,301 single cells from children, non-ICU and ICU adults during Acute and 841 Convalescent phases.

842 (G) Stacked barplot showing cellular composition of PBMCs in children, non-ICU and ICU adults 843 during Acute (top) and Convalescent (bottom) phases. 
A

B

B

\section{5}

48 ICU adults during Acute and Convalescent phases. $51 \mathrm{CD}^{+}$and $\mathrm{CD} 8^{+} \mathrm{T}$ cells.
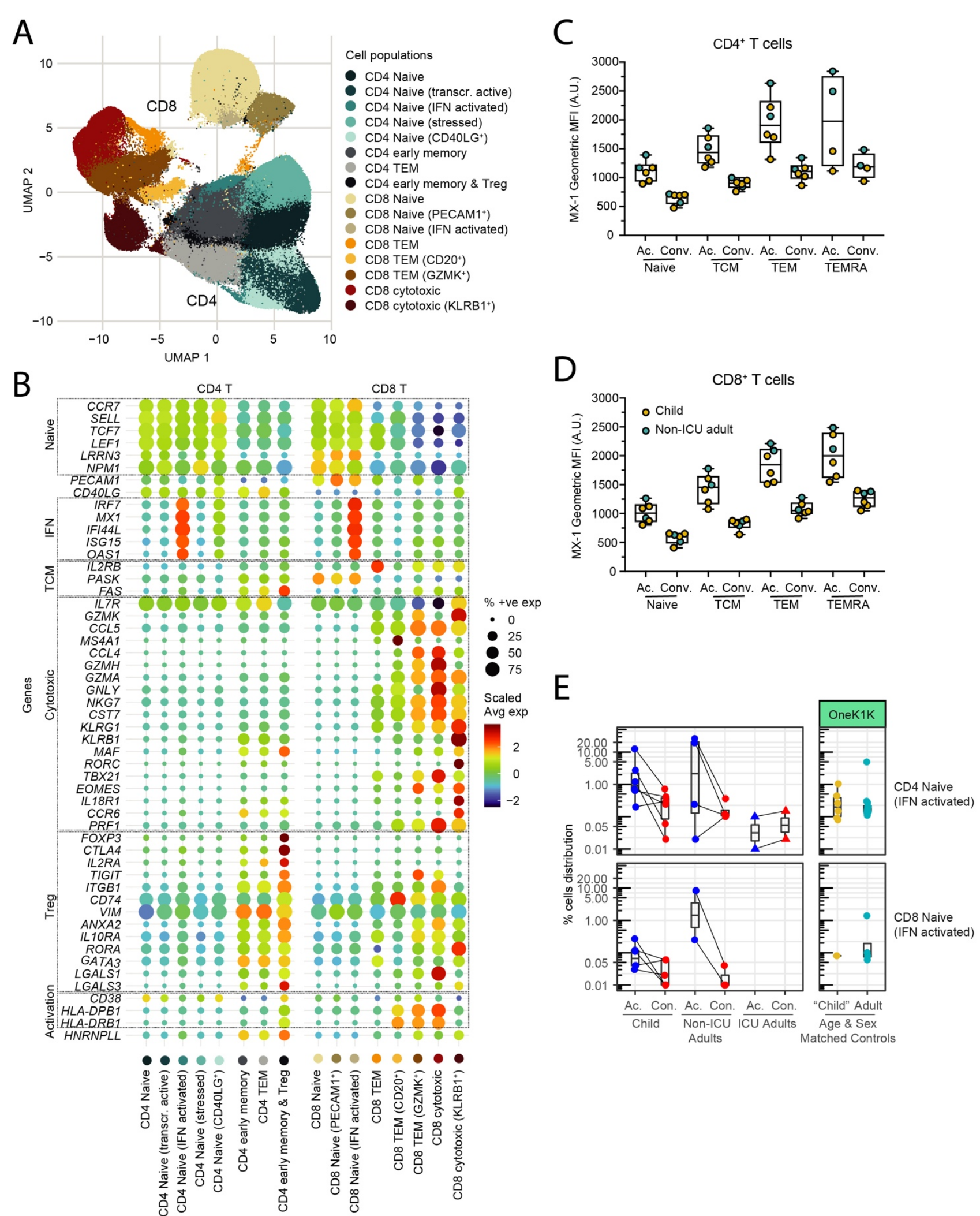

\section{Figure 2. Decomposition of the $T$ cell compartment in children and adults with COVID-19.}

(A) UMAP showing 171,393 $\mathrm{CD}^{+} \mathrm{T}$ cells and 127,069 $\mathrm{CD}^{+} \mathrm{T}$ cells from children, non-ICU and

(B) Expression of genes associated with the naïve, interferon response (IFN), T central memory (TCM), $\mathrm{T}$ cell cytotoxicity, regulatory $\mathrm{T}$ cell (Treg) and activation states by different subclusters of 
852 (C) Detection of interferon-induced MX-1 protein in subpopulations of $\mathrm{CD}^{+} \mathrm{T}$ cells during Acute 853 and Convalescence. Naïve $=\mathrm{CD}^{2} 5 \mathrm{RA}^{+} \mathrm{CD} 45 \mathrm{RO}^{-} ; \mathrm{TCM}=\mathrm{CD}^{-} \mathrm{RA}{ }^{-} \mathrm{CD} 45 \mathrm{RO}^{+} \mathrm{CCR}^{+} \mathrm{CD}^{+} \mathrm{L}^{+}$;

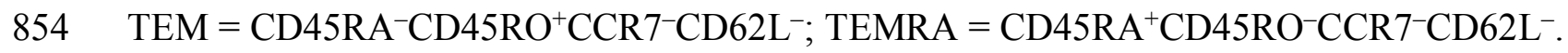

855 (D) Detection of interferon-induced MX-1 protein in subpopulations of $\mathrm{CD}^{+} \mathrm{T}$ cells during Acute 856 and Convalescence. $\mathrm{T}$ cell markers are as in (C).

857 (E) Detection of interferon-activated naïve $\mathrm{CD}^{+} \mathrm{T}$ cells (top) and $\mathrm{CD} 8^{+} \mathrm{T}$ cells (bottom) in children, 858 non-ICU and ICU adults during Acute and Convalescent phases (left) and in healthy age and sex859 matched donors in the OneK1K cohort (right). 
A

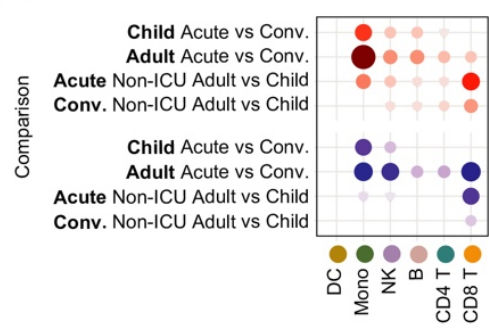

B

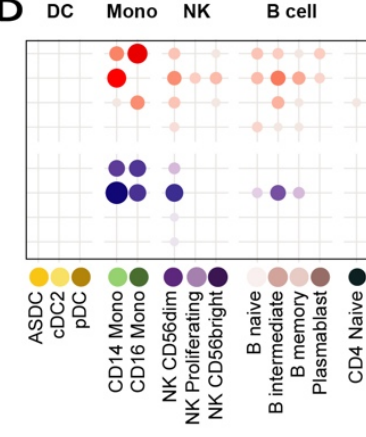

CD4 T
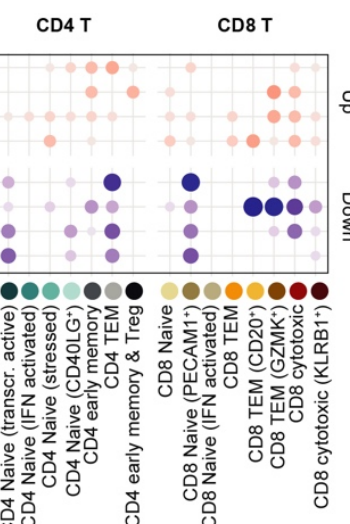

\# Up \# Down

DEG DEG

$0 \quad 0$

$10 \bigcirc 10$

$20 \quad 20$

$40 \bigcirc 40$

C

Figure 3. Transcriptomic differences between children and adults with mild COVID-19.

863 (A) Dotplot showing the number of differentially expressed genes in the innate (DC, monocyte and

$864 \mathrm{NK}$ cell) and adaptive (B, CD4 ${ }^{+} \mathrm{T}$ and $\mathrm{CD}^{+} \mathrm{T}$ cell) compartments between children and non-ICU 865 adults during Acute and Convalescent phases.

866 (B) Dotplot showing the number of differentially expressed genes in the innate and adaptive immune 867 cell subclusters between children and non-ICU adults during Acute and Convalescent phases.

868 (C) Expression of interferon response genes by innate immune cells from children, non-ICU and ICU 869 adults during Acute and Convalescence.

870 (D) Expression of interferon response genes by adaptive immune cells from children, non-ICU and 871 ICU adults during Acute and Convalescence. 
A
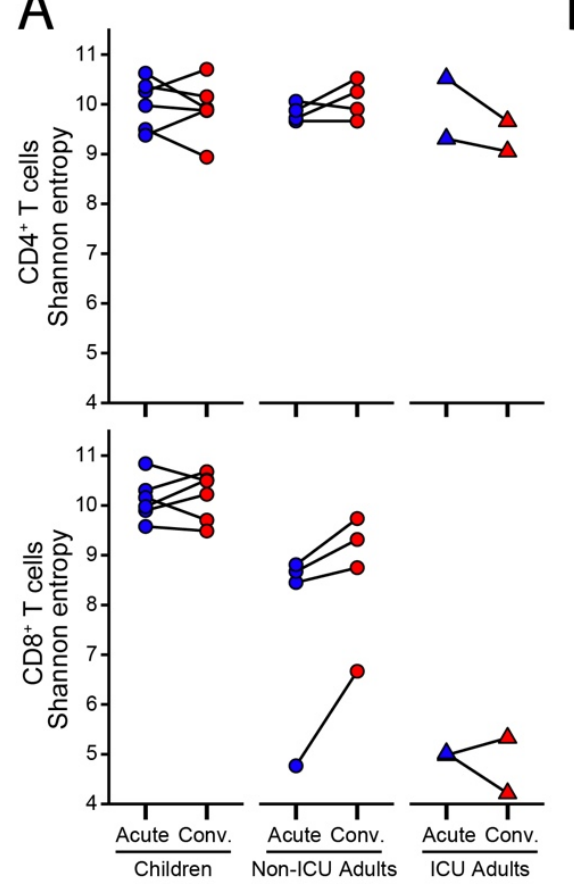

C

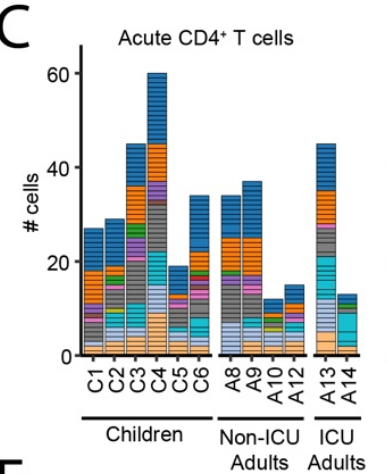

E

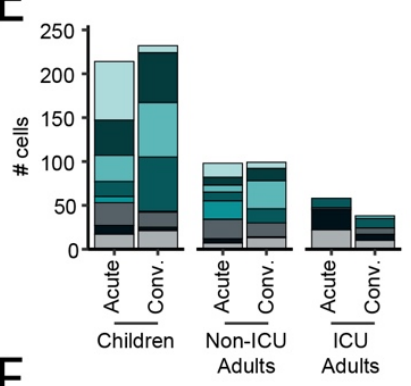

F

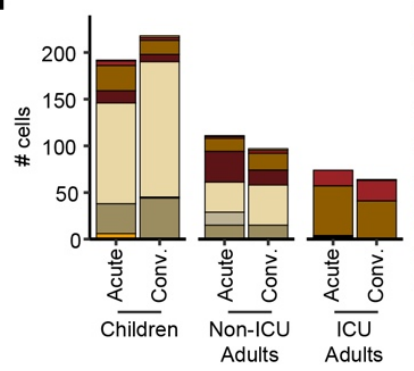

CD4 Naive

$\square$ CD4 TEM

$\square$ CD8 Naive

$\square$ CD8 cytotoxic

$\square$ CD8 TEM

B

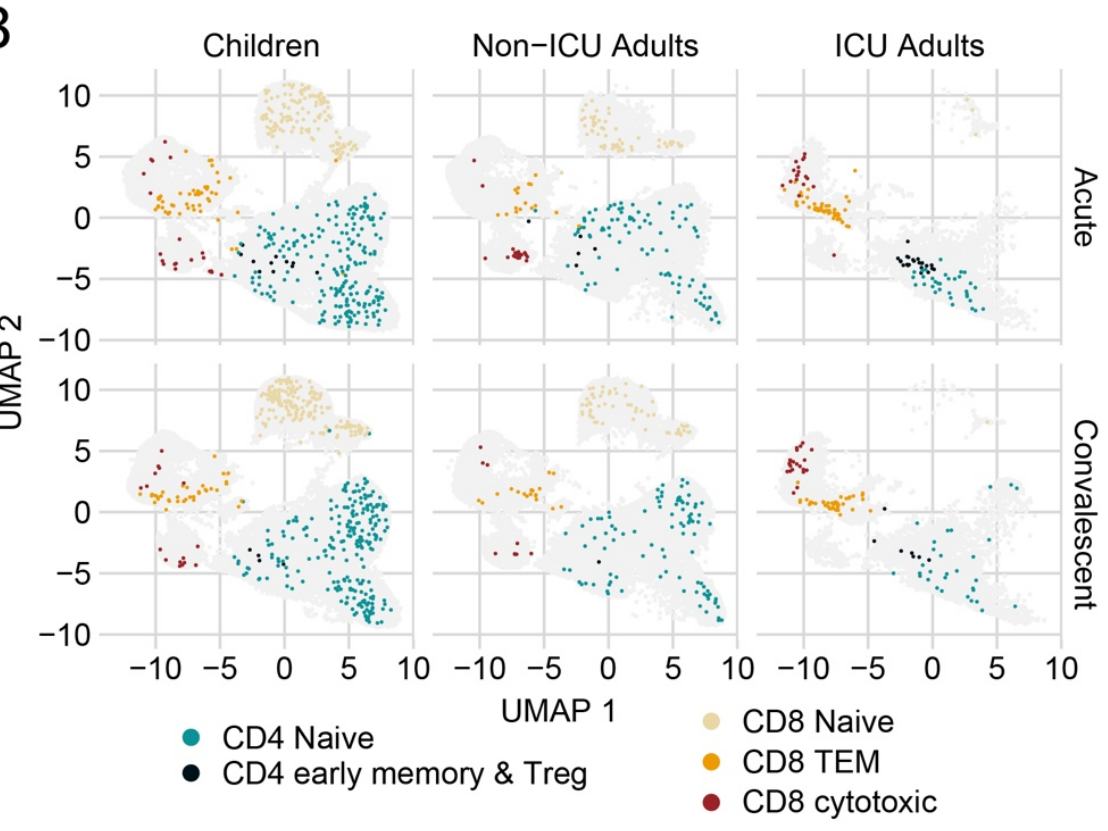

Conv. CD4+ $4^{+}$cells

D

Acute $C D 8^{+} T$ cells
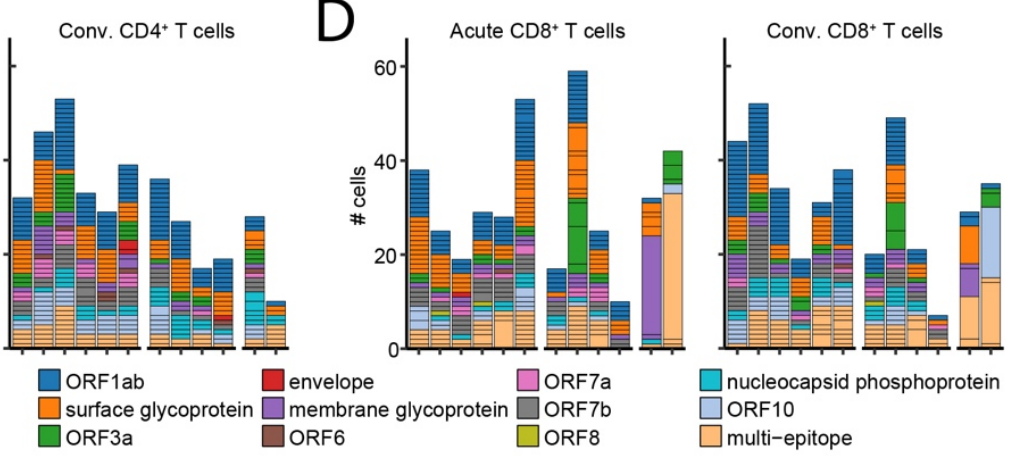

G

$\square$ CD4 Naive (CD40LG')

$\square$ CD4 Naive (stressed)

CD4 Naive (transcr. active)

$\square$ CD4 Naive (IFN activated)

$\square$ CD4 early memory

CD4 early memory \& Treg

$\square$ CD8 Naive (IFN activated)

$\square$ CD8 Naive (PECAM1 ${ }^{+}$)

CD8 cytotoxic (KLRB1+)

$\square$ CD8 TEM $\left(\mathrm{GZMK}^{+}\right)$
$\square \mathrm{CD} 8 \mathrm{TEM}\left(\mathrm{CD} 20^{+}\right)$
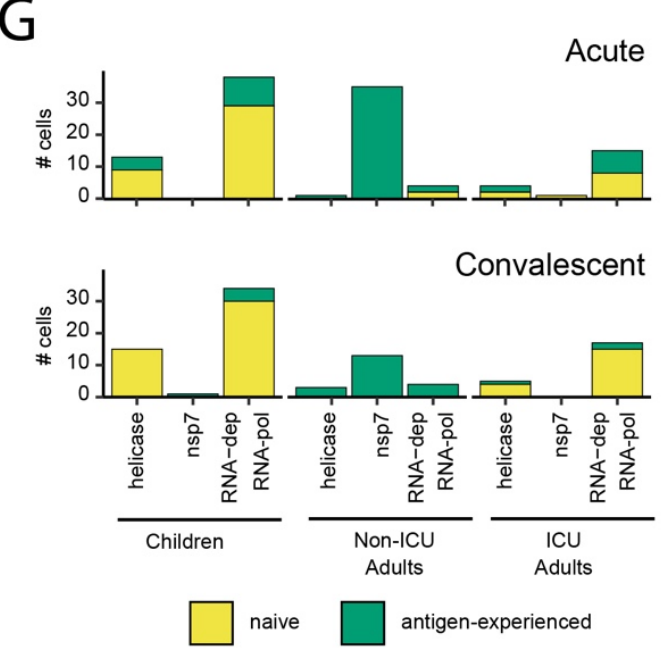

Figure 4. Clonal analysis of SARS-CoV-2-specific T cells.

874 (A) Shannon entropy score for $\mathrm{CD}^{+}$(top) and $\mathrm{CD}^{+}$(bottom) $\mathrm{T}$ cells in children, non-ICU and ICU

875 adults in Acute and Convalescent phases.

876 (B) Transcriptional state of T cells annotated as SARS-CoV-2-specific in children, non-ICU and ICU adults in Acute (top) and Convalescent (bottom) phases. 
878 (C) Epitope specificity of $\mathrm{CD}^{+} \mathrm{T}$ cells for different components of SARS-CoV-2 virus in children, 879 non-ICU and ICU adults in Acute (left) and Convalescent (right) phases. Each stack in the stacked 880 barplot represents a single clone.

881 (D) Epitope specificity of $\mathrm{CD}^{+} \mathrm{T}$ cells for different components of SARS-CoV-2 virus in children, 882 non-ICU and ICU adults in Acute (left) and Convalescent (right) phases. Each stack in the stacked 883 barplot represents a single clone.

884 (E) Transcriptional state of SARS-CoV-2-annotated of $\mathrm{CD}^{+} \mathrm{T}$ cells in children, non-ICU and ICU 885 adults in Acute and Convalescent phases.

886 (F) Transcriptional state of SARS-CoV-2-annotated of $\mathrm{CD}^{+} \mathrm{T}$ cells in children, non-ICU and ICU 887 adults in Acute and Convalescent phases.

888 (G) Number of RTC-specific T cells in children, non-ICU and ICU adults in Acute (top) and 889 Convalescent (bottom) phases. Naïve $\mathrm{CD}^{+}$and $\mathrm{CD}^{+} \mathrm{T}$ cells are yellow and antigen-experienced $\mathrm{T}$ 890 cells are green. 

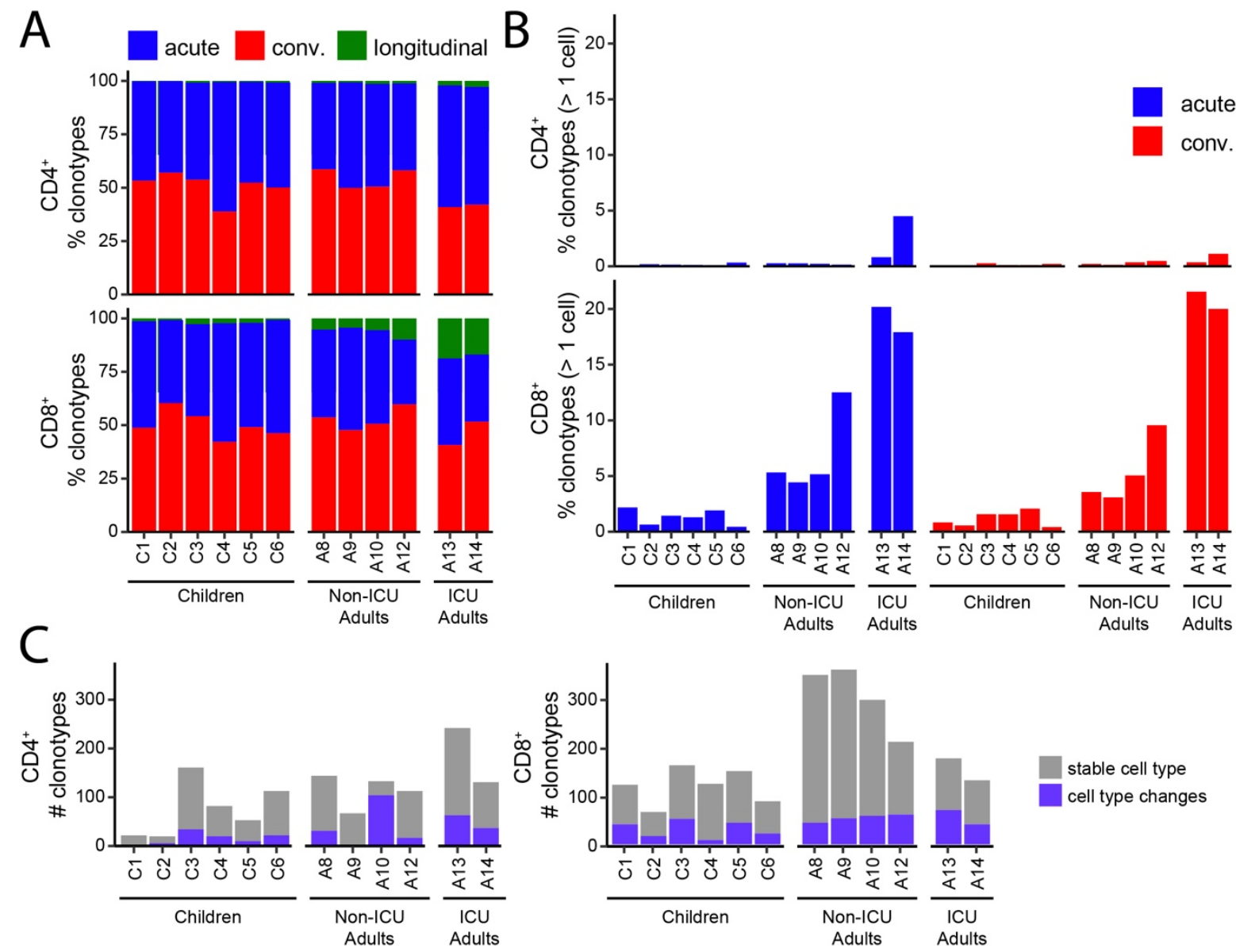

D
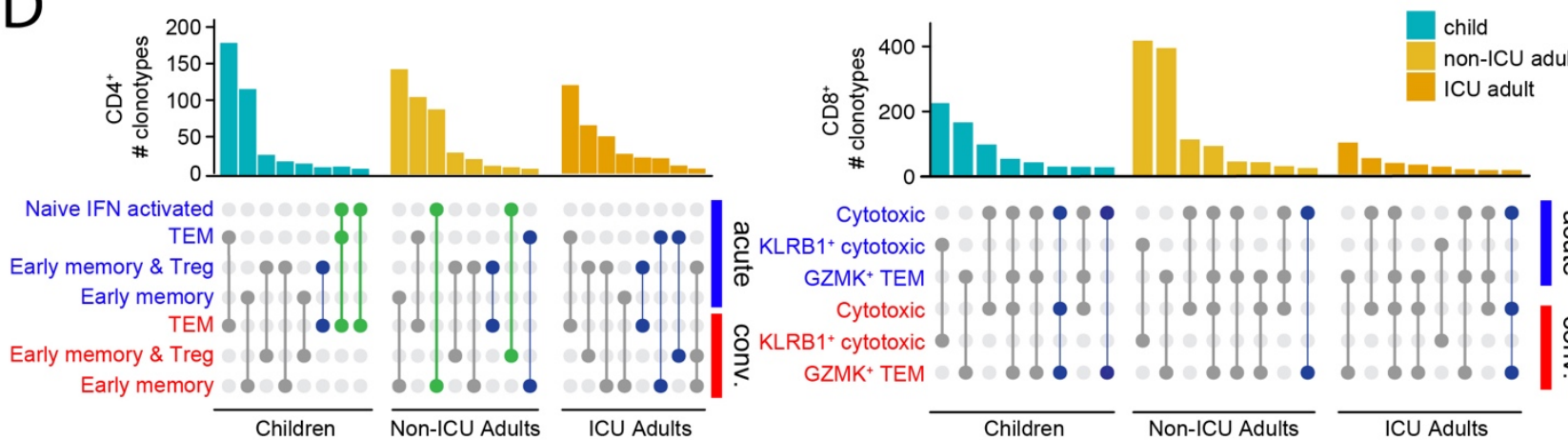

naive > memory

Ag-experienced > Ag-experienced stable cell type

$\mathrm{E}$
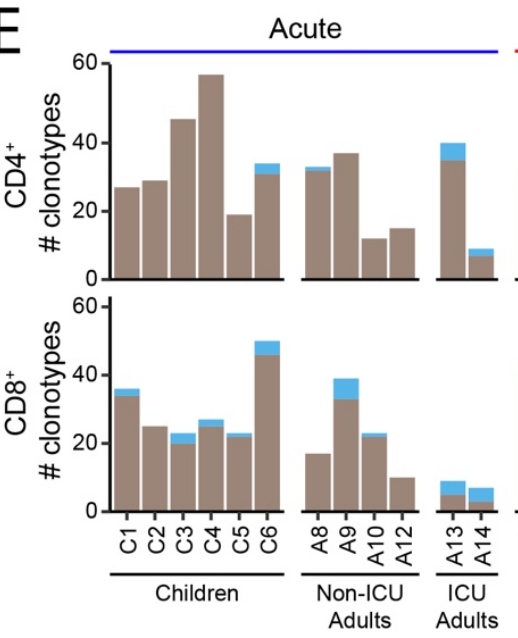

Conv.
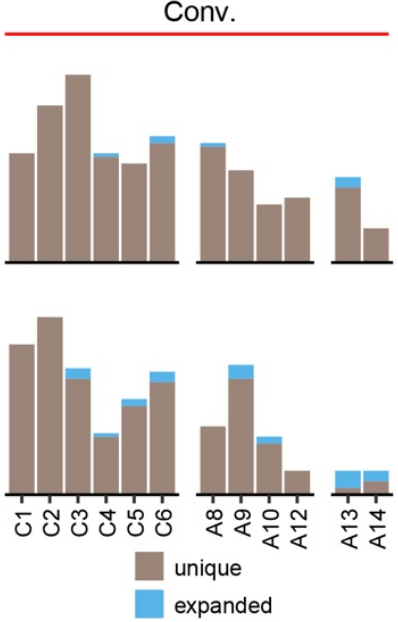

$\mathrm{F}$

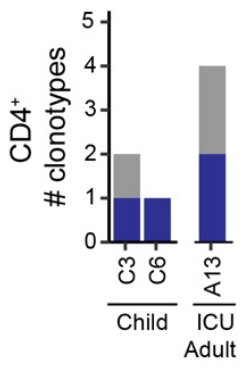

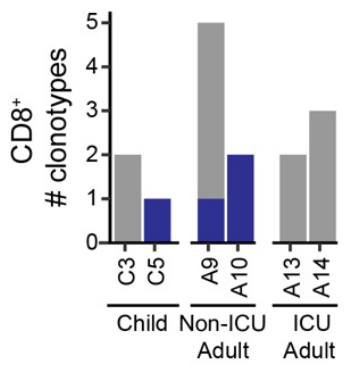

Ag-experienced > Ag-experienced stable cell type

Figure 5. Clonal dynamics of SARS-CoV-2-specific T cells. 
894 (A) Percentage of $\mathrm{CD}^{+}$(upper) and $\mathrm{CD}^{+}$(lower) clonotypes that are unique at the Acute (red) or 895 Convalescent (blue) phase of infection or present in both (green) for each subject.

896 (B) Number of $\mathrm{CD}^{+}$(upper) and $\mathrm{CD}^{+}$(lower) clonotypes that are detected at both the Acute and 897 Convalescent phase of infection (longitudinal clonotypes).

898 (C) Counts for $\mathrm{CD}^{+}$(left) and $\mathrm{CD}^{+}$(right) clonotypes coloured by whether their cell type remains 899 the same (grey) or changes (purple) between the Acute and Convalescent phases.

900 (D) Top 8 cell type distributions for $\mathrm{CD}^{+}$(left) and $\mathrm{CD}^{+}$(right) longitudinal clonotypes for children, 901 non-ICU adults and ICU adults. The barplots indicate the number of clonotypes with the cell type 902 distribution pattern depicted below each bar where a filled circle indicates that the cell type on the y903 axis is present. Distributions are coloured to indicate whether they represent transitions from naïve to 904 antigen-experienced (green), transitions between antigen-experienced compartments (blue) or are the 905 same cell type across the two timepoints (grey).

906 (E) Clonotype counts for SARS-CoV-2-annotated clonotypes for all donors for the $\mathrm{CD}^{+}$(upper) and $907 \mathrm{CD}^{+}$(lower) compartments coloured by whether the clonotype was unique (light brown) or 908 expanded (light blue) at either the Acute (left) or Convalescent (right) phase.

909 (F) Clonotype counts for longitudinal SARS-CoV-2-annotated CD4 ${ }^{+}$(left) and CD8 ${ }^{+}$(right) T cells 910 for the subset of donors that harbor them. Clonotypes are grouped and coloured by whether they have 911 the same cell type at both timepoints (grey) or altered their cell types between Acute and Convalescent 912 phases (dark blue). 
A
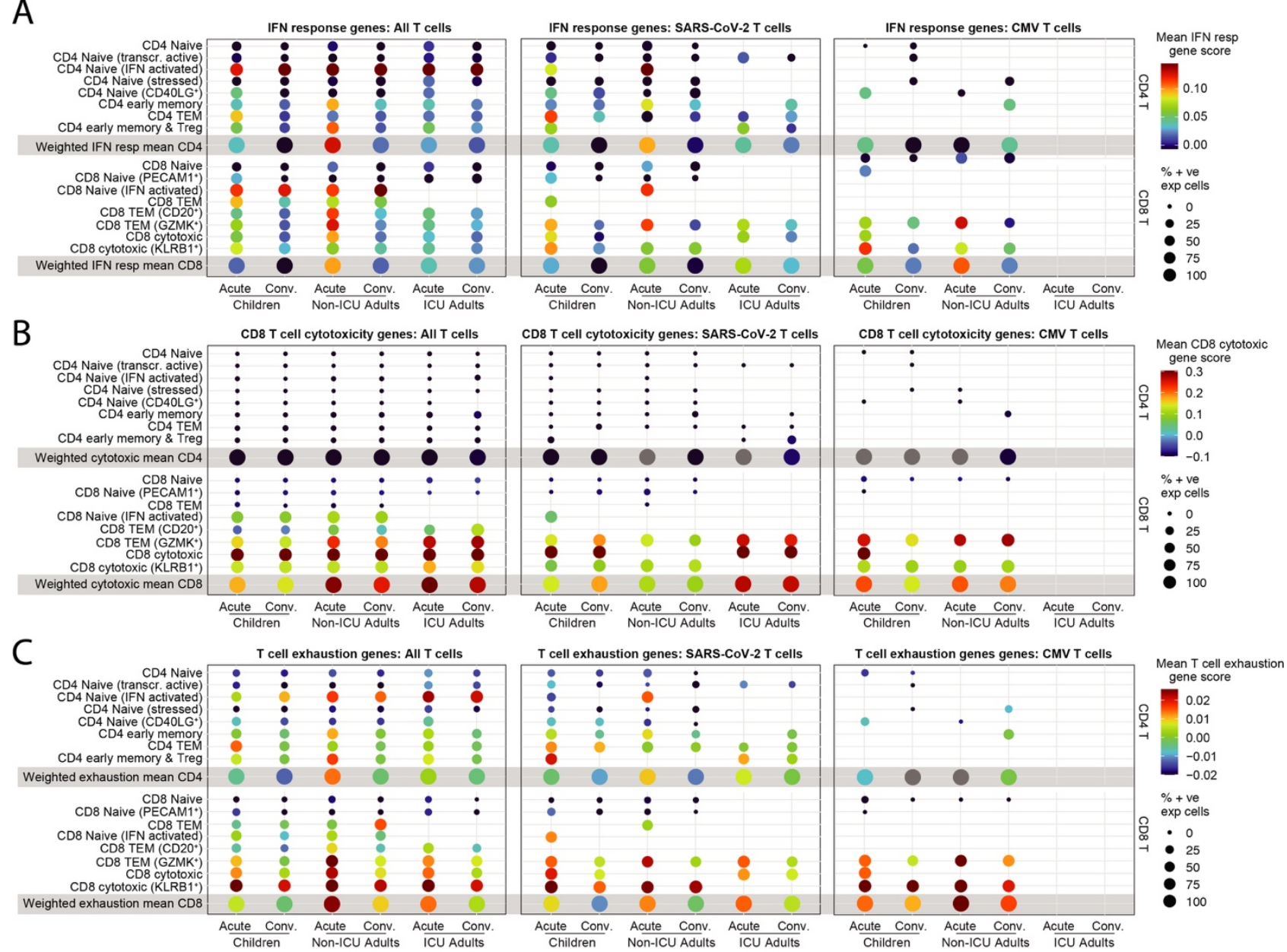

915 Figure 6. $\mathbf{T}$ cell interferon activation, cytotoxicity and exhaustion states.

916 (A) Interferon response gene scores for all T cells (left), SARS-CoV-2-specific T cells (middle) and 917 CMV-specific T cells (right) in children, non-ICU and ICU adults in Acute and Convalescent phases. 918 (B) $\mathrm{CD}^{+} \mathrm{T}$ cell cytotoxicity gene scores for all $\mathrm{T}$ cells (left), SARS-CoV-2-specific $\mathrm{T}$ cells (middle) 919 and CMV-specific T cells (right) in children, non-ICU and ICU adults in Acute and Convalescent 920 phases.

921 (C) $\mathrm{T}$ cell exhaustion gene scores for all $\mathrm{T}$ cells (left), SARS-CoV-2-specific $\mathrm{T}$ cells (middle) and 922 CMV-specific T cells (right) in children, non-ICU and ICU adults in Acute and Convalescent phases. 
A

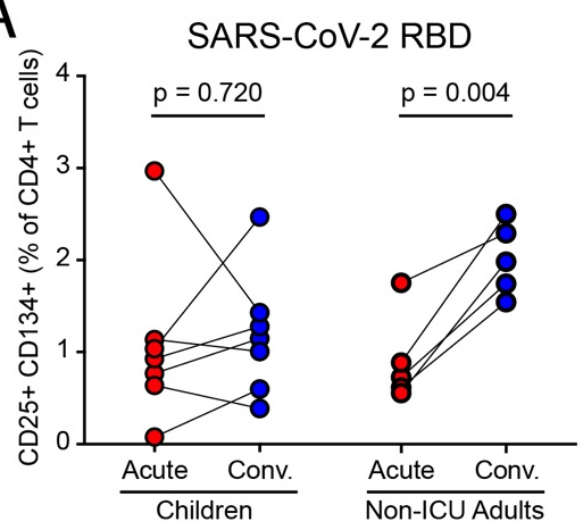

C

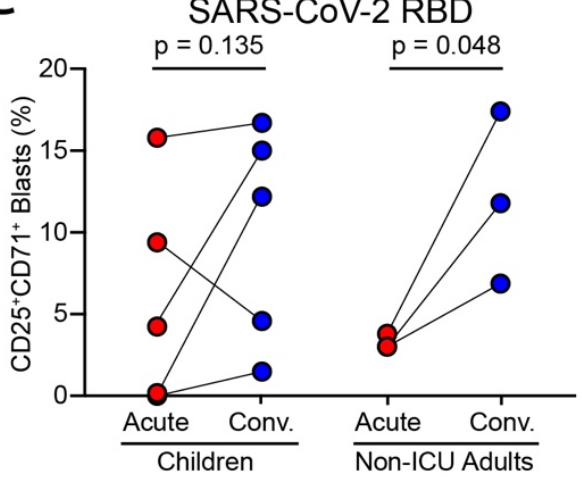

$E$

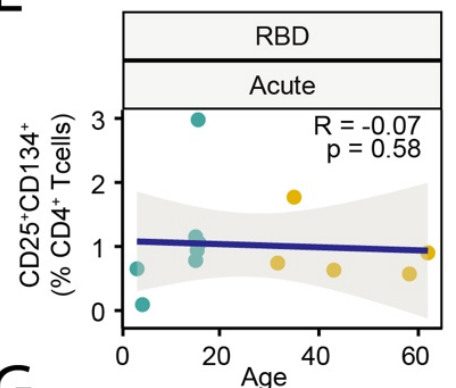

G

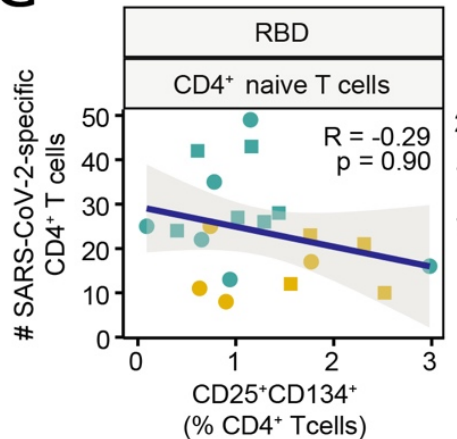

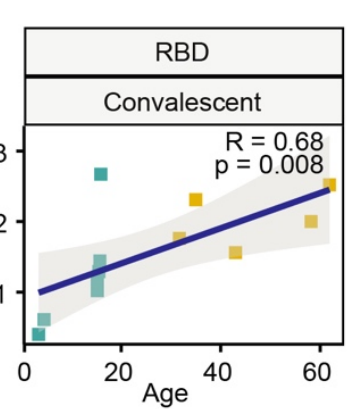

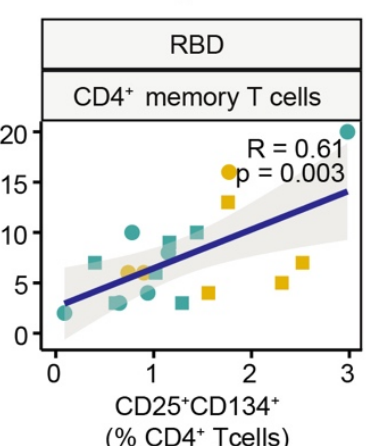

B

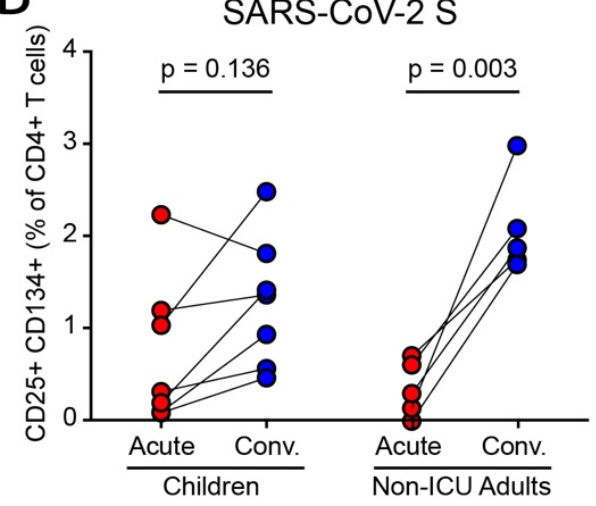

D

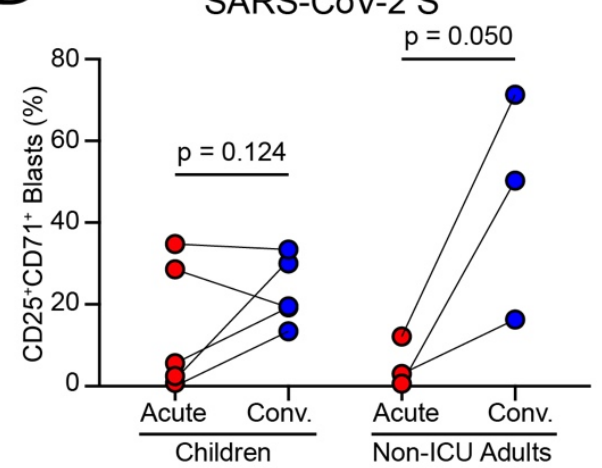

$\mathrm{F}$
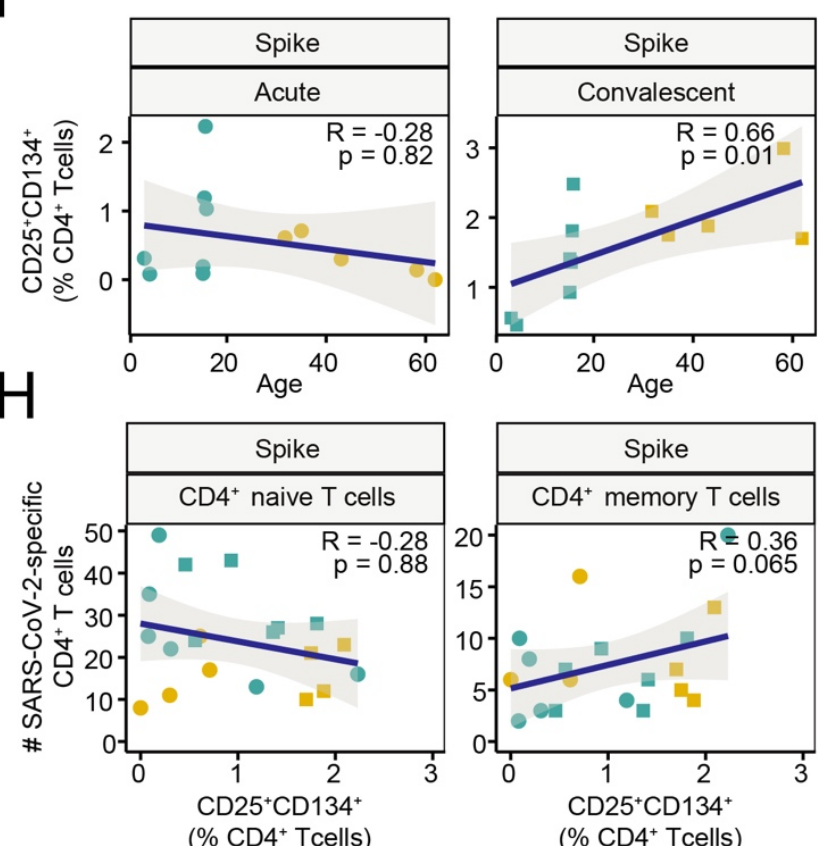

Figure 7. Memory $T$ cell responses to $S A R S-C o V-2$ in children and adults.

(A) Frequency of $\mathrm{CD} 25^{+} \mathrm{CD} 134^{+} \mathrm{CD}^{+} \mathrm{T}$ cells in cultures of PBMCs stimulated with recombinant

927 SARS-CoV-2 RBD protein from children and non-ICU adults in Acute and Convalescent phases.

928 (B) Frequency of $\mathrm{CD} 25^{+} \mathrm{CD} 134^{+} \mathrm{CD} 4^{+} \mathrm{T}$ cells in cultures of PBMCs stimulated with recombinant

929 SARS-CoV-2 S protein from children and non-ICU adults in Acute and Convalescent phases.

930 (C) $\mathrm{CD}^{+} \mathrm{T}$ cell proliferative response in cultures of PBMCs stimulated with recombinant SARS-

931 CoV-2 RBD protein from children and non-ICU adults in Acute and Convalescent phases. 
932 (D) $\mathrm{CD}^{+} \mathrm{T}$ cell proliferative response in cultures of PBMCs stimulated with recombinant SARS933 CoV-2 S protein from children and non-ICU adults in Acute and Convalescent phases.

934 (E) Linear regression of $\mathrm{CD} 25^{+} \mathrm{CD} 134^{+}$response to $\mathrm{RBD}$ protein by $\mathrm{CD} 4^{+} \mathrm{T}$ cells with age in Acute 935 (left) and Convalescent (right) phases.

936 (F) Linear regression of $\mathrm{CD} 25^{+} \mathrm{CD} 134^{+}$response to $\mathrm{S}$ protein by $\mathrm{CD} 4^{+} \mathrm{T}$ cells with age in Acute (left) 937 and Convalescent (right) phases.

938 (G) Linear regression of $\mathrm{CD} 25^{+} \mathrm{CD} 134^{+}$response to $\mathrm{RBD}$ protein by $\mathrm{CD}^{+} \mathrm{T}$ cells with number of 939 SARS-CoV-2-specific naïve (left) and memory (right) T cells.

940 (H) Linear regression of $\mathrm{CD} 25^{+} \mathrm{CD} 134^{+}$response to $\mathrm{S}$ protein by $\mathrm{CD} 4^{+} \mathrm{T}$ cells with number of SARS941 CoV-2-specific naïve (left) and memory (right) T cells. 


\section{Supplementary Figure legends}

A

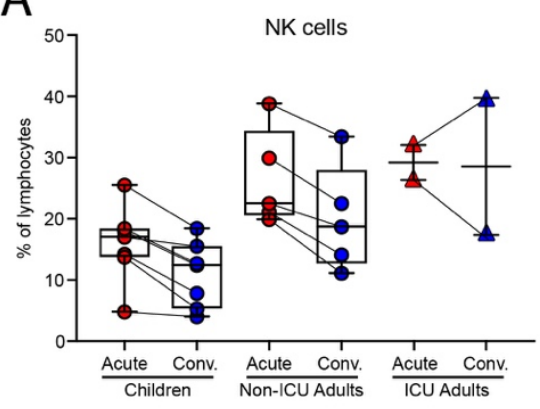

$\mathrm{D}$

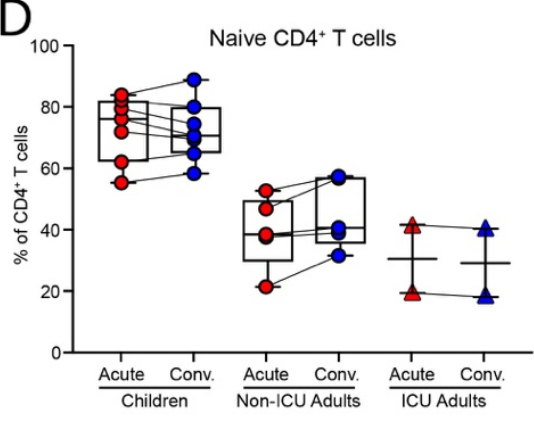

$\mathrm{E}$
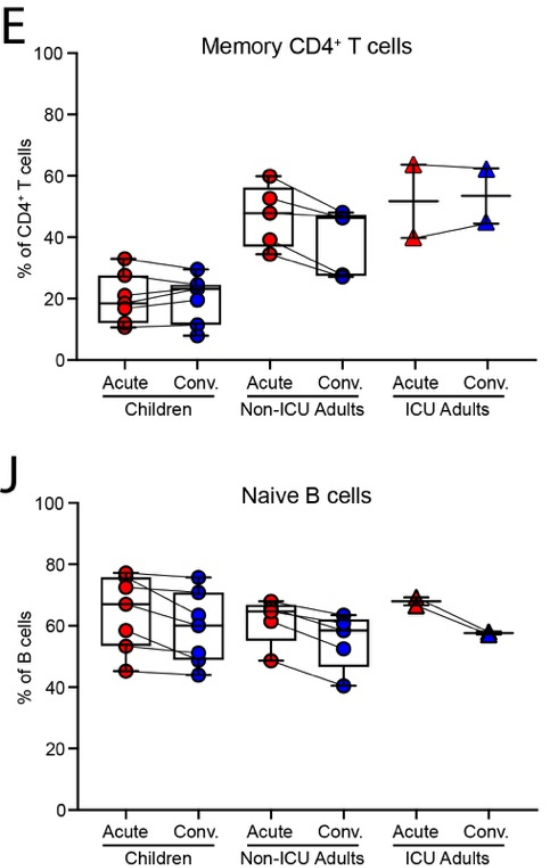

B

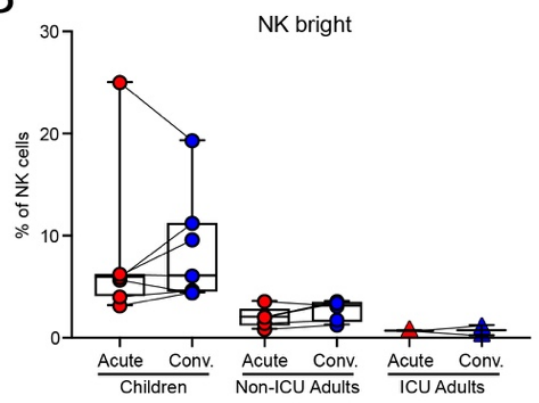

$\mathrm{F}$

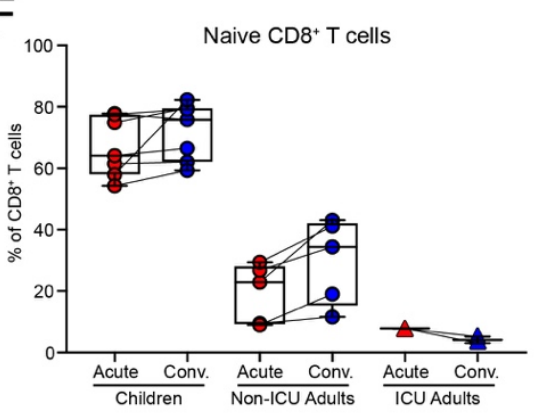

$\mathrm{H}_{50} \quad$ CD8* TEM

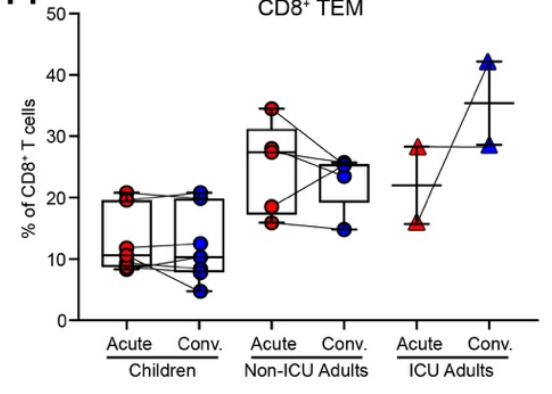

$\mathrm{K}$

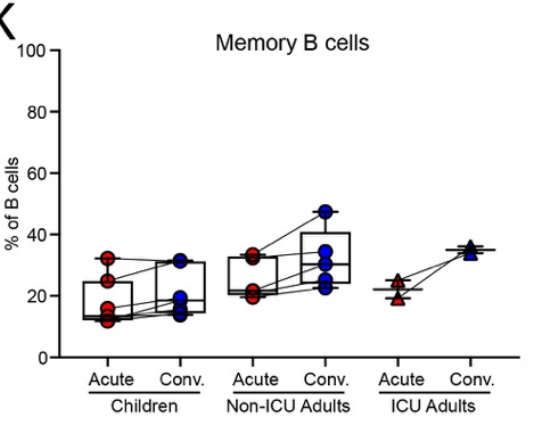

C

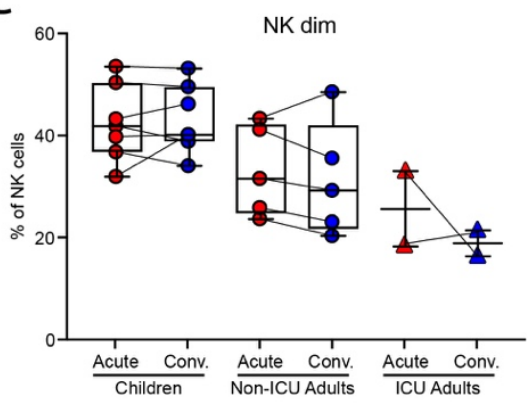

G

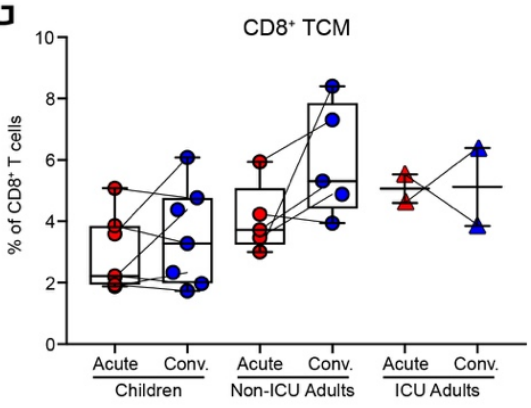

I

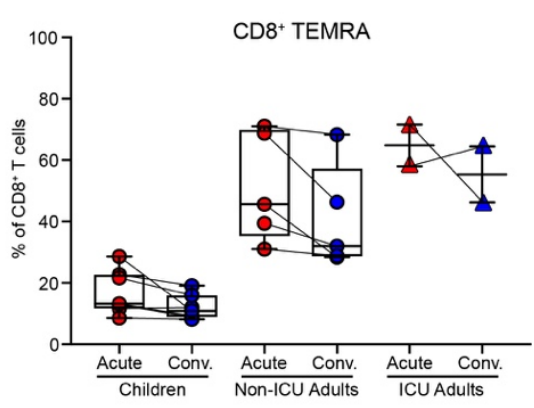

$\mathrm{L}$

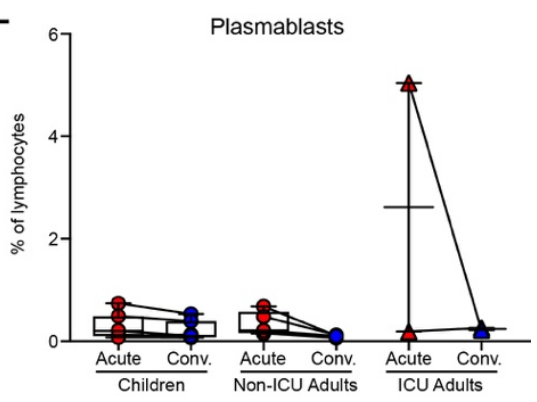

Figure S1. Flow cytometric analysis of PBMCs in children and adults with COVID-19.

947 (A) NK cells.

948 (B) NK bright cells.

949 (C) NK dim cells.

950 (D) Naïve $\mathrm{CD} 4^{+} \mathrm{T}$ cells.

951 (E) Memory $\mathrm{CD}^{+} \mathrm{T}$ cells.

952 (F) Naïve $\mathrm{CD} 8^{+} \mathrm{T}$ cells.

953 (G) $\mathrm{CD}^{+}$central memory $\mathrm{T}$ cells (TCM).

954 (H) $\mathrm{CD}^{+}$effector memory $\mathrm{T}$ cells (TEM). 
955 (I) $\mathrm{CD}^{+}$terminally differentiated effector memory $\mathrm{T}$ cells (TEMRA).

956 (J) Naïve B cells.

957 (K) Memory B cells.

958 (L) Plasmablasts.

959 
A

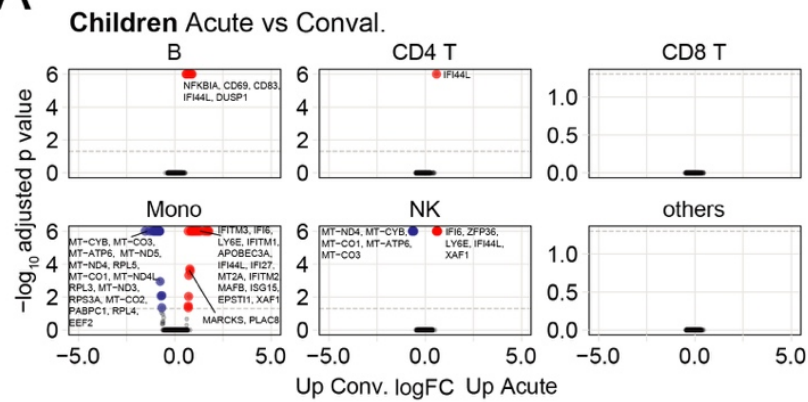

A

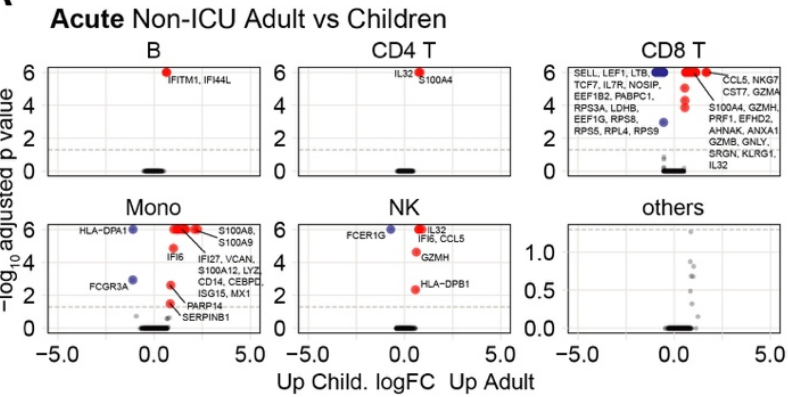

B

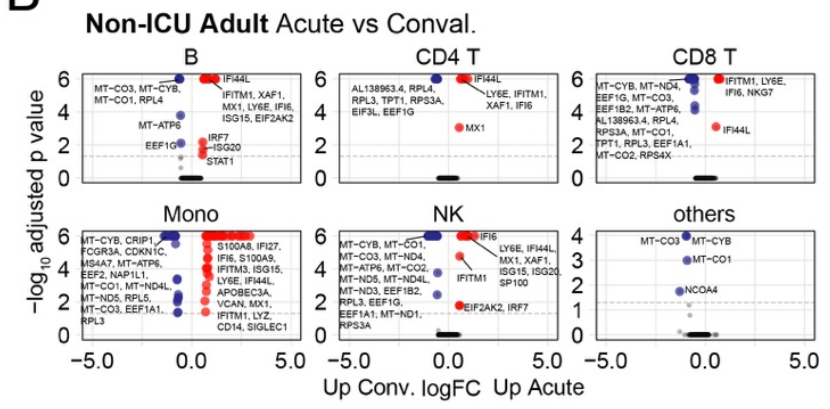

B

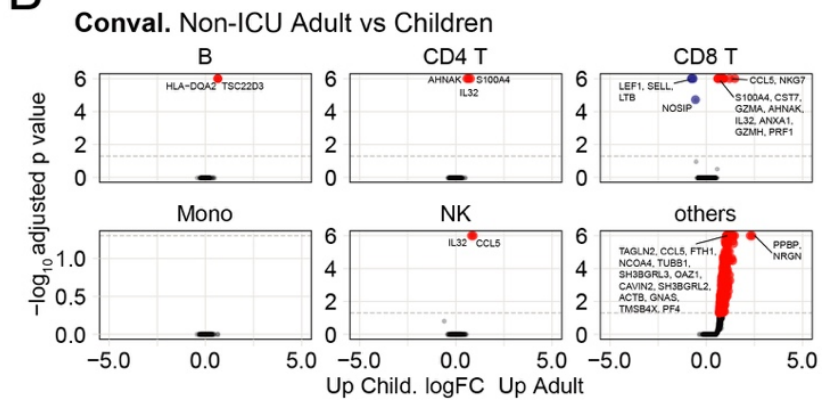

961 Figure S2. Volcano plots showing top 50 differentially expressed genes.

962 (A) Between acute and convalescent samples in children.

963 (B) Between acute and convalescent samples in non-ICU adults.

964 (C) Between non-ICU adults and children in the acute phase.

965 (D) Between non-ICU adults and children in the convalescent phase. 
METHODS

\section{EXPERIMENTAL MODELS AND SUBJECT DETAILS}

Mild/asymptomatic COVID-19 children and adult family members

Participants were recruited under the Immunophenotyping of COVID-19 and other Severe Acute

Respiratory Infections Study (2020/PID00920) approved by the Sydney Children's Hospital Network (SCHN) Human Research Ethics Committee (2020/ETH00837). Potential child participants were identified through admission to the Children's Hospital at Westmead following a positive SARSCoV-2 reverse transcriptase polymerase chain reaction (RT-PCR). Families were approached and both children and positive household adults were consented to longitudinal blood sampling. Blood used in these analyses were collected in lithium heparin and serum-separation tubes (Becton Dickinson, USA), and collected both acutely (within 14 days of first positive RT-PCR) and approximately one-month post infection. All patients were ambulant with either mild symptoms, consisting of a cough or sneeze, or asymptomatic (WHO Clinical Progress Scale of 1 out of 10). All consented samples used in these analyses were collected between $23^{\text {rd }} \mathrm{July}, 2020$ and $24^{\text {th }}$ October, 2020.

\section{Severe COVID-19 patients}

986 Participants were recruited under the South-East Queensland COVID Consortium study approved by the Gold Coast Hospital and Health Service Human Research Ethics Committee (HREC/2020/QGC/63082). Patient recruitment was undertaken by research team members at the Gold Coast University Hospital. A waiver of informed consent, with the opportunity to opt-out was used for this study. Both patients were elderly males with severe COVID-19 who were intubated and ventilated ICU (WHO Clinical Progress Scale of 7 out of 10). Acute samples were taken on the $14^{\text {th }}$ April 2020. A13 had second sample 8 days later on the 22 ${ }^{\text {nd }}$ April, 2020 and A14 had convalescent sample taken on the $10^{\text {th }}$ September, 2020.

\section{METHOD DETAILS}

PBMC processing and cryopreservation

PBMCs were diluted 1:1 with PBS and the mix overlaid in a 2:1 ratio with Ficoll-Paque in 50ml Falcon tube. Cells were centrifuged at $1700 \mathrm{rpm}$ for 30 minutes with brake off at room temperature $\left(18-21^{\circ} \mathrm{C}\right)$. Mononuclear cells at the interface were collected and transferred to a new Falcon tube and washed $\times 2$ with ice-cold PBS/0.5\% FBS by centrifugation at $1300 \mathrm{rpm}$ for 8 minutes with brake on. Cells were resuspended in $5 \mathrm{ml}$ culture media (RPMI/1\% HEPES) for counting with a haemocytometer and Trypan blue. Cells were then resuspended in $500 \mu$ culture media at a 
1003 concentration of $2 \times 10^{7} / \mathrm{ml}$ and $500 \mu \mathrm{l}$ freezing media $(200 \mathrm{ml}$ culture media, $200 \mathrm{ml} \mathrm{FBS}$ and $100 \mathrm{ml}$

1004 DMSO) and cryovials transferred to the $-80^{\circ} \mathrm{C}$ freezer in a Styrofoam box for $24-48$ hours before 1005 storage in liquid nitrogen. Frozen PBMCs were thawed and centrifuged at 400g for 5 minutes. 1006 Samples were washed with twice with $4 \%$ FBS/PBS and stained with DAPI $(0.1 \mu \mathrm{g} / \mathrm{ml})$ for 5 minutes 1007 at room temperature prior sorting of live $\mathrm{DAPI}^{-}$cells on the AriaIII (BD Biosciences)

\section{Serum antibody testing}

1010 Serum was prepared from clotted tubes by centrifugation at $1000 \mathrm{~g}$ for 10 minutes. IgG titres to the 1011 SARS-CoV-2 Spike protein were measured by our previously published high sensitivity flow 1012 cytometry cell-based assay (Tea et al., 2021) which has been modeled on autoantibody detection test 1013 used in clinical diagnostic testing of neuroimmunological disorders (Lopez et al., 2022; Tea et al., 1014 2019). HEK293 cells were transfected to express early-clade SARS-CoV-2 Spike antigens. Diluted 1015 serum (1:80) was added to live Spike-expressing cells. Codon-optimised, wild-type SARS-CoV-2 1016 strain Wuhan Spike protein ORF with 18 amino acids deleted from the cytoplasmic tail was cloned 1017 within the MCS of a lentiviral expression vector, pLVX-IRES-ZsGreen1, using EcoRI and XbaI 1018 restriction sites, resulting in pSpike-IRES-ZsGreen vector. All synthetic gene fragments were ordered 1019 through IDT. Cells were then incubated with Alexa Fluor 647-conjugated anti-human $\operatorname{IgG}(\mathrm{H}+\mathrm{L})$ 1020 (ThermoFisher Scientific). Cell events were acquired on LSRII flow cytometer (BD Biosciences, 1021 USA), and median fluorescence intensity (MFI), a proxy of antibody titres was analysed. The 1022 threshold for a positive result was determined if the delta MFI $(\triangle \mathrm{MFI}=\mathrm{MFI}$ transfected cells - MFI 1023 untransfected cells) was above the positive threshold (mean $\triangle \mathrm{MFI}+4 \mathrm{SD}$ of 24 pre-pandemic age1024 matched controls) in at least two of three quality-controlled experiments. The sensitivity of the assay 1025 was superior to several commercial assays at 98\% (95\% CI: 92-99\%) (Tea et al., 2021). Data were 1026 analysed using FlowJo 10.4.1 (TreeStar, USA), Excel (Microsoft, USA) and GraphPad Prism 1027 (GraphPad Software, USA).

\section{Serum cytokine bead array}

1030 We used the BD Cytometric Bead Array (CBA) kit to measure serum cytokines. Cytokine standards 1031 were made up in assay diluent as per the manufacturer's instructions. Capture bead mix was made up 1032 in Capture Bead Diluent for Serum/Plasma to a final concentration of $25 \mu \mathrm{L} /$ test. Serum samples 1033 were diluted 1:1 in assay diluent. To each well $25 \mu \mathrm{L}$ of beads was added, followed by $25 \mu \mathrm{L}$ of 1034 standard or $25 \mu \mathrm{L}$ of diluted serum sample. Samples were incubated with beads in the dark for 1 hour 1035 at room temp. Detection master mix was prepared as per the manufacturer's instructions and $25 \mu \mathrm{L}$ 1036 added to each sample and then samples incubated for a further 2 hours in the dark at room 1037 temperature. Beads were then washed twice in wash buffer and then acquired on BD FACS Canto II 
1038 flow cytometer (BD Pharmingen). Analysis was performed on FCAP array software v 3.0 (BD

1039 Biosciences). Cytokine concentrations were imported into R (version 4.1.2), log transformed, and 1040 visualized with ggplot2 (version 3.3.5).

\section{Flow cytometry}

1043 Thawed cells were resuspended in 2\% FBS/PBS and plated in a 96-well V-bottom plate. Antibody 1044 cocktails were prepared in FACS buffer (0.1\% BSA/0.1\% sodium azide/PBS). Cells were pelleted by 1045 centrifugation at $490 \mathrm{~g}$ for 5 minutes at $4^{\circ} \mathrm{C}$. Cells were then stained with $50 \mu \mathrm{L}$ of Zombie UV Fixable 1046 viability dye (diluted 1/500 in PBS) for 20 minutes on ice in the dark. Cells were washed 3 times with 1047 FACS buffer. Cells were then incubated with $50 \mu \mathrm{L}$ of blocking agents (normal mouse serum 1/20, 1048 Fc block 1/10) for 15 minutes on ice. Antibody cocktails were prepared in FACS Buffer and $50 \mu \mathrm{L}$ 1049 added to each sample and then incubated for 30 minutes on ice in the dark. Cells were washed 3 times 1050 in FACS buffer and then fixed by resuspending in $150 \mu \mathrm{L}$ of $1 \%$ formaldehyde for 20 minutes at room 1051 temperature. Cells were then washed and resuspended in FACS buffer and run on FACSymphony 1052 (BD Pharmingen). Samples were analysed using FlowJo software (Tree Star).

Intracellular staining for MX-1 was performed for $1 \times 10^{5}$ thawed PBMC using the Transcription Factor Buffer Set (BD Biosciences) according to the manufacturer's directions. Permeabilized cells were stained with CD3-PerCP-Cy5.5, CD4-BUV395, CD8-BUV805, CD45RA-BUV737, CD27APC-R700 (BD Biosciences) and $1 \mu \mathrm{g}$ MX-1-AF647 (Abcam) according to manufacturer's directions and analysed on a 5-laser Fortessa X20 (BD Biosciences) as previously described (Zaunders et al., 2020).

\section{Recombinant RBD and S protein}

1062 Expression plasmids encoding His-tagged SARS-CoV-2 RBD (residues 319 to 541 of SARS-CoV-2

1063 S protein) or S protein (with a C-terminal trimerization domain) were cloned into pCEP4 vector and 1064 transfected into Expi293F (ThermoFisher Scientific) and the proteins expressed for 7 days at $37^{\circ} \mathrm{C}$ 1065 (Rouet et al., 2021). The proteins were captured from the clarified cell culture using TALON resin 1066 (ThermoFisher Scientific) and eluted with imidazole. The full trimeric S protein was further purified 1067 by size exclusion chromatography (Superose 6 resin) to remove dissociated S1 and S2 domains. The protein purity was assessed by visualization on SDS-PAGE gel.

1071 Antigen-specific CD4 T-cells responding to recall antigens were measured in cultures of 300,000 1072 PBMC in $200 \mu \mathrm{l} /$ well of a 96-well plate, in Iscove's Modified Dulbecco's Medium (IMDM; 
1073 Thermofisher, Waltham, MA, USA) containing 10\% human serum (Wayne Dyer, Australian Red

1074 Cross Lifeblood, Sydney, Australia), and incubated for $44-48 \mathrm{hr}$ incubation, in a 5\% $\mathrm{CO}_{2}$ incubator,

1075 as previously described (Zaunders et al., 2009). Separate cultures were incubated with different 1076 antigens including: (i) culture medium only negative control well; (ii) anti-CD3/anti-CD28/anti-CD2

$1077 \mathrm{~T}$ cell activator (1/100 dilution) polyclonal positive control well; (iii) $5 \mu \mathrm{g} / \mathrm{ml}$ recombinant SARS-

$1078 \mathrm{CoV}-2 \mathrm{~S}$ trimer; and (iii) $5 \mu \mathrm{g} / \mathrm{ml}$ recombinant SARS-CoV-2 RBD. $100 \mu 1$ of PBMC from the 1079 respective cultures were stained with CD3-PerCP-Cy5.5, CD4-FITC, CD25-APC, and CD134-PE 1080 (BD Biosciences, San Jose, CA, USA), and live/dead fixable NIR dead cell stain kit reagent according 1081 to manufacturer's directions and analysed on a 5-laser Fortessa X20 (BD Biosciences) as previously 1082 described (Zaunders et al., 2020). Antigen-specific $\mathrm{CD}^{+} \mathrm{T}$ cells were gated and expressed as $1083 \mathrm{CD}^{2} 5^{+} \mathrm{CD} 134^{+} \%$ of $\mathrm{CD}^{+} \mathrm{CD}^{+}$live $\mathrm{T}$ cells as previously described (Zaunders et al., 2009). Cultures 1084 were classified as positive for antigen-specific $\mathrm{CD} 4^{+} \mathrm{T}$ cells if the $\mathrm{CD} 25^{+} \mathrm{CD} 134^{+} \%$ of $\mathrm{CD} 4^{+} \mathrm{CD} 3^{+}$ 1085 T cells was $\geq 0.2 \%$ (Hsu et al., 2012).

\section{Antigen-specific $\mathbf{T}$ cell proliferation and RNA extraction}

1088 Antigen-specific T cell proliferation was measured in cultures of PBMC incubated with different controls and antigens in separate wells as above for the OX40 assays, except cells were incubated for 7 days. $100 \mu 1$ of PBMC were then stained with CD3-PerCP-Cy5.5, CD4-FITC, CD25-APC, and

1091 CD71-BV650 according to manufacturer's directions and analysed on a 5-laser Fortessa X20 (BD 1092 Biosciences) as previously described (Zaunders et al., 2020). Antigen-specific proliferating CD4 ${ }^{+} \mathrm{T}$ 1093 cells were gated as \% of Forward Scatter high and $\mathrm{CD} 25^{+} \mathrm{CD} 71^{+} \mathrm{CD} 4^{+} \mathrm{CD} 3^{+} \mathrm{T}$ cells. Proliferating 1094 cells remaining in the cultures were further expanded by incubating for a further 7 days with 20 1095 IU/mL IL-2 (Roche Life Science Products). After expansion, cells from each well were used for RNA 1096 extraction, using the Maxwell RSC SimplyRNA Tissue kit and the Maxwell RSC automated extraction system (Promega, Madison, WI) as previously described (Suzuki et al., 2021).

\section{Single cell RNA transcriptome and TCR repertoire sequencing}

1100 Single cell transcriptomic libraries were generated using the 5'v2 Gene expression and immune 1101 profiling kit (10x Genomics). Viable PBMCs were sorted into 2\% FBS/PBS and cell counts were 1102 performed using a haemocytometer. Up to 40,000 cells were loaded into each lane of Chromium Next 1103 GEM Chip K Single Cell Kit (10x Genomics) to achieve a recovery cell number of approximately 110420,000 cells. Subsequent cDNA and TCR libraries were generated according to manufacturer's 1105 instructions. Generated libraries were sequenced on the NovaSeq S4 flow cell (Illumina) at Read $1=$ $110628, \mathrm{i} 7$ index $=10, \mathrm{i} 5$ index $=10$ and Read 2: 90 cycles according to manufacturer's instructions. 


\section{Transcriptomic analysis}

1109 Pre-processing of raw sequencing files

1110 Single-cell sequencing data was demultiplexed, aligned and quantified using Cell Ranger (10x 1111 Genomics) against the human reference genome (10x Genomics, July 7, 2020 release) with default 1112 parameters.

1114 Filtering and quality control was performed using Seurat (Stuart et al., 2019) on raw data containing 1115522,926 cells where 433,301 cells were retained satisfying thresholds of both $<10 \%$ mitochondria 1116 content and number of genes between 200 and 5000. 'SCTransform' was used for normalization with 1117 regression of batch, gender and cell mitochrondria content covariates (Hafemeister and Satija, 2019).

\section{Annotation of cell identities}

1120 Cell annotation was performed using 'reference-based mapping' pipeline implemented in Azimuth 1121 algorithm in Seurat (Hao et al., 2021). Azimuth annotated T cells were re-clustered and T cell sub1122 populations were manually annotated based on UMAP clustering and markers defined by 1123 'FindAllMarkers' function in Seurat.

\section{Differential gene expression analysis}

1126 Raw counts from defined cell populations were normalised using scran / scater (Lun et al., 2016;

1127 McCarthy et al., 2017) and differential gene expression analysis was performed using Limma voom 1128 (Law et al., 2014) with regression of Batch and Gender covariates. DGE analysis was not performed 1129 on dendritic cells (all sub populations) and CD8 IFN activated Naïve cell populations due to low cell 1130 numbers $(<100$ cells $)$ sampled in the dataset.

\section{Gene signature scores}

1133 Gene signature scores (Table S4) was generated using 'AddModuleScore' function in Seurat. Cell 1134 sub-populations with less than 5 cells within sample groups were excluded from the analysis. To 1135 compare the gene signatures across different sub-populations within sample groups, gene scores were weighted based on the proportion of positive expressing cells within the sub-population.

1138 The interferon gene signature was generated from aggregating unique interferon response genes 1139 sourced from (Hadjadj et al., 2020; Kim et al., 2021; Lee et al., 2020; Szabo et al., 2019). T cell 1140 exhaustion signature was sourced from (Utzschneider et al., 2020). CD8 ${ }^{+}$cytotoxic $\mathrm{T}$ cell signature 1141 was sourced from (Szabo et al., 2019). 


\section{Analysis of the OneK1K cohort}

1144 OneK1K Cohort Study was established to investigate the effects of genetic variation on gene 1145 expression at single cell resolution. Original cohort includes more than 1000 individuals recruited 1146 from the Royal Hobart Hospital, Hobart Eye Surgeons as well as from the retirement villages within 1147 Hobart, Australia prior to the COVID-19 pandemic. We have selected 26 age- and sex- matched 1148 individuals from this cohort to compare cell type proportions with the COVID-19 patients. The study 1149 was approved by the Tasmanian Health and Medical Human Research Ethics Committee 1150 (H0012902). Informed consent was obtained from all participants.

1152 Peripheral blood samples were collected into vacutainer tubes containing either FICOLL ${ }^{\mathrm{TM}}$ and 1153 sodium heparin (8mL CPT ${ }^{\mathrm{TM}}$; BD Australia, North Ryde, NSW; 362753) or K2EDTA (10mL; BD 1154 Australia, North Ryde, NSW; Catalogue: 366643). During single cell library preparation equal 1155 numbers of live cells were combined for 12-14 samples per pool. Pooled single cell suspensions 1156 partitioned and barcoded using the 10X Genomics Chromium Controller and the Single Cell 3' 1157 Library and Gel Bead Kit version 2 (PN-120237). The pooled cells were super-loaded onto the 1158 Chromium Single Cell Chip A (PN-120236) to target 20,000 cells per pool. Libraries for all samples 1159 were multiplexed and sequenced across five 2x150 cycle flow cells on an Illumina NovaSeq 6000.

1160 The Cell Ranger Single Cell Software Suite (version 2.2.0) was used to process data produced by the 1161 Illumina NovaSeq 6000 sequencer into transcript count tables. Raw base calls from multiple flow 1162 cells were demultiplexed into separate pools of samples. Reads from each pool were then mapped to 1163 the GRCh38 genome using STAR (Dobin et al., 2013). Cells for each individual were identified using 1164 the Demuxlet computational tool (Kang et al., 2018). The most likely individual for each droplet was 1165 determined using the genotype posterior probability estimate from imputation of 265,053 exonic 1166 SNPs (R2>0.3 and MAF>0.05). In all approaches, $\boldsymbol{\alpha}$ was set to 0.5 , assuming a 50/50 ratio and other 1167 parameters were kept as default. Droplets which were identified as doublets by both Demuxlet and 1168 Scrublet (Wolock et al., 2019) were removed from the dataset.

We used our COVID-19 dataset as a reference to guide the cell type classification of the OneK1K 1171 cohort using the Symphony approach (Kang et al., 2021). First, we selected the top 5000 highly 1172 variable genes conditioned by batch information and normalized the data using factor normalization 1173 and logarithmic transformation as implemented in Seurat. Next, we centered and standardized the 1174 normalized gene expression data for the highly variable genes and stored the means and standard 1175 deviations for each gene across all cells. We performed singular value decomposition on the scaled 1176 data. We applied harmony to align the gene expression embeddings by batch using a theta value of 2 1177 and performing 100 clustering iterations and a maximum of 20 rounds of harmony clustering and 
correction. We applied the same normalization strategy for the OneK1K data and projected the data onto the reference by scaling the OneK $1 \mathrm{~K}$ data using the reference means and standard deviation and aligning the data using Symphony. Finally, we assign the cell type labels to the OneK1K cells using a lazy K-nearest neighbor classifier with $\mathrm{k}=5$.

\section{TCR repertoire analysis}

Following processing with 10X Genomics cellranger vdj (v6.1.2) using the human reference the resulting VDJ contigs were post-processed using stand-alone IgBLAST (v1.14) (Ye et al., 2013) to generate further alignment details. Where a single barcode was associated with more than one chain for either the TRB or TRA loci the VDJ with the highest UMI count was retained. Clonal lineages were defined by IgBLAST called V, J and CDR3 amino acid sequences for both TRA and TRB, if available, or by a single chain if paired chains were not available. Expanded clonotypes were defined within each sample (subject and time point) as those observed across 2 or more cells, while longitudinal clonotypes were those from a subject that were observed at both the acute and convalescent timepoints.

TRBs of reported specificities were collected from immuneCODE Multiplex Identification of T cell Receptor Antigen specificity (MIRA) release 002.2 (Nolan et al., 2020), and VDJdb v2021-09-05 (Bagaev et al., 2020). Additional TRBs were added from (Low et al., 2021), (Lineburg et al., 2021) and (Francis et al., 2022). TRBs were formatted to consistent format, where ambiguous TRBVs reported as a separate entry were created for each TRB.

To account for the private SARS-CoV-2 responses that may not be captured in the public databases, bulk TRB sequencing was undertaken following proliferation of the outputs of the OX40 assays. The bulk sequencing assay was adapted from (Shugay et al., 2014). RNA was reverse transcribed to cDNA that incorporated a 10bp universal molecular identifier using a modification of the SmartSeq2 protocol (Picelli et al., 2014) described in (Massey et al, 2020).

TRBs of reported or inferred specificity were mapped to 10x VDJs by matching of TRB clonotype labels. Where the same TRB was reported to bind multiple epitopes, all epitopes were associated with the TRB clonotype. SARS-CoV-2-annotated clonotypes were defined as any clonotype matching a SARS-CoV-2 reported VDJ regardless of poly-specificity or those observed in the bulk repertoire sequencing from the proliferation assay at an enrichment of at least 64-fold above baseline. 
1212 TCR clonotype and annotation data were merged with 10x GEX via cell barcodes. Repertoire metrics

1213 were summarised in RStudio (v1.4.1106, RStudio Team (2021). RStudio: Integrated Development

1214 Environment for R. RStudio, PBC, Boston, MA URL http://www.rstudio.com) using tidyverse

1215 package (Wickham et al., 2019). Shannon entropy was calculated for $\mathrm{CD}^{+}$and $\mathrm{CD}^{+} \mathrm{T}$ cell

1216 compartments for each subject to explore the diversity (Shannon, 1948). Clonotype distribution

1217 across cell types and time points was explored using Upset plots (Lex et al., 2014) as implemented

1218 by the ComplexHeatmap package (Gu et al., 2016).

1219

1220 Statistics

1221 Statistical analysis was performed using Prism software (GraphPad) or in R. We used unpaired

1222 Student's t-test to compare between 2 groups and paired Student's t-tests to compare longitudinal

1223 differences within the same individuals. We used the one-way ANOVA with Tukey's correction for

1224 comparisons between multiple groups. We used Fisher's exact test for $2 \times 2$ contingency tables and

1225 Chi-square for $2 \times 3$ contingency tablesw. Correlation between variables was measured by Pearson's 1226 correlation coefficient with a one-sided Student's t-test. 


\section{References}

Bagaev, D.V., Vroomans, R.M.A., Samir, J., Stervbo, U., Rius, C., Dolton, G., Greenshields-Watson, A., Attaf, M., Egorov, E.S., Zvyagin, I.V., et al. (2020). VDJdb in 2019: database extension, new analysis infrastructure and a T-cell receptor motif compendium. Nucleic Acids Res 48, D1057D1062.

Dobin, A., Davis, C.A., Schlesinger, F., Drenkow, J., Zaleski, C., Jha, S., Batut, P., Chaisson, M., and Gingeras, T.R. (2013). STAR: ultrafast universal RNA-seq aligner. Bioinformatics 29, 15-21. Francis, J.M., Leistritz-Edwards, D., Dunn, A., Tarr, C., Lehman, J., Dempsey, C., Hamel, A., Rayon, V., Liu, G., Wang, Y., et al. (2022). Allelic variation in class I HLA determines CD8(+) T cell repertoire shape and cross-reactive memory responses to SARS-CoV-2. Sci Immunol 7, eabk3070. Gu, Z., Eils, R., and Schlesner, M. (2016). Complex heatmaps reveal patterns and correlations in multidimensional genomic data. Bioinformatics 32, 2847-2849.

Hadjadj, J., Yatim, N., Barnabei, L., Corneau, A., Boussier, J., Smith, N., Pere, H., Charbit, B., Bondet, V., Chenevier-Gobeaux, C., et al. (2020). Impaired type I interferon activity and inflammatory responses in severe COVID-19 patients. Science 369, 718-724.

Hafemeister, C., and Satija, R. (2019). Normalization and variance stabilization of single-cell RNAseq data using regularized negative binomial regression. Genome Biol 20, 296.

Hao, Y., Hao, S., Andersen-Nissen, E., Mauck, W.M., 3rd, Zheng, S., Butler, A., Lee, M.J., Wilk, A.J., Darby, C., Zager, M., et al. (2021). Integrated analysis of multimodal single-cell data. Cell 184, 3573-3587 e3529.

Hsu, D.C., Zaunders, J.J., Plit, M., Leeman, C., Ip, S., Iampornsin, T., Pett, S.L., Bailey, M., Amin, J., Ubolyam, S., et al. (2012). A novel assay detecting recall response to Mycobacterium tuberculosis: Comparison with existing assays. Tuberculosis (Edinb) 92, 321-327.

Kang, H.M., Subramaniam, M., Targ, S., Nguyen, M., Maliskova, L., McCarthy, E., Wan, E., Wong, S., Byrnes, L., Lanata, C.M., et al. (2018). Multiplexed droplet single-cell RNA-sequencing using natural genetic variation. Nat Biotechnol 36, 89-94.

Kang, J.B., Nathan, A., Weinand, K., Zhang, F., Millard, N., Rumker, L., Moody, D.B., Korsunsky, I., and Raychaudhuri, S. (2021). Efficient and precise single-cell reference atlas mapping with Symphony. Nature communications 12, 5890.

Kim, M.H., Salloum, S., Wang, J.Y., Wong, L.P., Regan, J., Lefteri, K., Manickas-Hill, Z., Gao, C., Li, J.Z., Sadreyev, R.I., et al. (2021). Type I, II, and III Interferon Signatures Correspond to Coronavirus Disease 2019 Severity. J Infect Dis 224, 777-782.

Law, C.W., Chen, Y., Shi, W., and Smyth, G.K. (2014). voom: Precision weights unlock linear model analysis tools for RNA-seq read counts. Genome Biol 15, R29. 
1262 Lee, J.S., Park, S., Jeong, H.W., Ahn, J.Y., Choi, S.J., Lee, H., Choi, B., Nam, S.K., Sa, M., Kwon, 1263 J.S., et al. (2020). Immunophenotyping of COVID-19 and influenza highlights the role of type I 1264 interferons in development of severe COVID-19. Sci Immunol 5.

1265 Lex, A., Gehlenborg, N., Strobelt, H., Vuillemot, R., and Pfister, H. (2014). UpSet: Visualization of 1266 Intersecting Sets. IEEE Trans Vis Comput Graph 20, 1983-1992.

1267 Lineburg, K.E., Grant, E.J., Swaminathan, S., Chatzileontiadou, D.S.M., Szeto, C., Sloane, H., 1268 Panikkar, A., Raju, J., Crooks, P., Rehan, S., et al. (2021). CD8(+) T cells specific for an 1269 immunodominant SARS-CoV-2 nucleocapsid epitope cross-react with selective seasonal 1270 coronaviruses. Immunity 54, 1055-1065 e1055.

1271 Lopez, J.A., Houston, S.D., Tea, F., Merheb, V., Lee, F.X.Z., Smith, S., McDonald, D., Zou, A., 1272 Liyanage, G., Pilli, D., et al. (2022). Validation of a Flow Cytometry Live Cell-Based Assay to Detect 1273 Myelin Oligodendrocyte Glycoprotein Antibodies for Clinical Diagnostics. J Appl Lab Med 7, 12127425.

1275 Low, J.S., Vaqueirinho, D., Mele, F., Foglierini, M., Jerak, J., Perotti, M., Jarrossay, D., Jovic, S., 1276 Perez, L., Cacciatore, R., et al. (2021). Clonal analysis of immunodominance and cross-reactivity of 1277 the CD4 T cell response to SARS-CoV-2. Science 372, 1336-1341.

1278 Lun, A.T., McCarthy, D.J., and Marioni, J.C. (2016). A step-by-step workflow for low-level analysis 1279 of single-cell RNA-seq data with Bioconductor. F1000Res 5, 2122.

1280 McCarthy, D.J., Campbell, K.R., Lun, A.T., and Wills, Q.F. (2017). Scater: pre-processing, quality 1281 control, normalization and visualization of single-cell RNA-seq data in R. Bioinformatics 33, 117912821186.

1283 Nolan, S., Vignali, M., Klinger, M., Dines, J.N., Kaplan, I.M., Svejnoha, E., Craft, T., Boland, K., 1284 Pesesky, M., Gittelman, R.M., et al. (2020). A large-scale database of T-cell receptor beta (TCRbeta) 1285 sequences and binding associations from natural and synthetic exposure to SARS-CoV-2. Res Sq.

1286 Picelli, S., Faridani, O.R., Bjorklund, A.K., Winberg, G., Sagasser, S., and Sandberg, R. (2014). Full1287 length RNA-seq from single cells using Smart-seq2. Nat Protoc 9, 171-181.

1288 Rouet, R., Mazigi, O., Walker, G.J., Langley, D.B., Sobti, M., Schofield, P., Lenthall, H., Jackson, 1289 J., Ubiparipovic, S., Henry, J.Y., et al. (2021). Potent SARS-CoV-2 binding and neutralization 1290 through maturation of iconic SARS-CoV-1 antibodies. MAbs 13, 1922134.

1291 Shannon, C.E. (1948). A mathematical theory of communication. The Bell System Technical Journal $12927,379-423$.

1293 Shugay, M., Britanova, O.V., Merzlyak, E.M., Turchaninova, M.A., Mamedov, I.Z., Tuganbaev, 1294 T.R., Bolotin, D.A., Staroverov, D.B., Putintseva, E.V., Plevova, K., et al. (2014). Towards error1295 free profiling of immune repertoires. Nature methods 11, 653-655. 
1296

1297

1298

1299

1300

1301

1302

1303

1304

1305

1306

1307

1308

1309

1310

1311

1312

1313

1314

1315

1316

1317

1318

1319

1320

1321

1322

1323

1324

1325

1326

1327

1328

1329

1330

Stuart, T., Butler, A., Hoffman, P., Hafemeister, C., Papalexi, E., Mauck, W.M., 3rd, Hao, Y., Stoeckius, M., Smibert, P., and Satija, R. (2019). Comprehensive Integration of Single-Cell Data. Cell 177, 1888-1902 e1821.

Suzuki, K., Levert, A., Yeung, J., Starr, M., Cameron, J., Williams, R., Rismanto, N., Stark, T., Druery, D., Prasad, S., et al. (2021). HIV-1 viral blips are associated with repeated and increasingly high levels of cell-associated HIV-1 RNA transcriptional activity. AIDS 35, 2095-2103.

Szabo, P.A., Levitin, H.M., Miron, M., Snyder, M.E., Senda, T., Yuan, J., Cheng, Y.L., Bush, E.C., Dogra, P., Thapa, P., et al. (2019). Single-cell transcriptomics of human T cells reveals tissue and activation signatures in health and disease. Nat Commun 10, 4706.

Tea, F., Lopez, J.A., Ramanathan, S., Merheb, V., Lee, F.X.Z., Zou, A., Pilli, D., Patrick, E., van der Walt, A., Monif, M., et al. (2019). Characterization of the human myelin oligodendrocyte glycoprotein antibody response in demyelination. Acta Neuropathol Commun 7, 145.

Tea, F., Ospina Stella, A., Aggarwal, A., Ross Darley, D., Pilli, D., Vitale, D., Merheb, V., Lee, F.X.Z., Cunningham, P., Walker, G.J., et al. (2021). SARS-CoV-2 neutralizing antibodies: Longevity, breadth, and evasion by emerging viral variants. PLoS Med 18, e1003656.

Utzschneider, D.T., Gabriel, S.S., Chisanga, D., Gloury, R., Gubser, P.M., Vasanthakumar, A., Shi, W., and Kallies, A. (2020). Early precursor T cells establish and propagate T cell exhaustion in chronic infection. Nat Immunol 21, 1256-1266.

Wickham, H. (2007). Reshaping Data with the reshape Package. Journal of Statistical Software 21, 1 -20 .

Wickham, H., Averick, M., Bryan, J., Chang, W., McGowan, L.D.A., François, R., Grolemund, G., Hayes, A., Henry, L., and Hester, J. (2019). Welcome to the Tidyverse. Journal of open source software 4, 1686.

Wolock, S.L., Lopez, R., and Klein, A.M. (2019). Scrublet: Computational Identification of Cell Doublets in Single-Cell Transcriptomic Data. Cell Syst 8, 281-291 e289.

Ye, J., Ma, N., Madden, T.L., and Ostell, J.M. (2013). IgBLAST: an immunoglobulin variable domain sequence analysis tool. Nucleic Acids Res 41, W34-40.

Zaunders, J., Munier, C.M.L., McGuire, H.M., Law, H., Howe, A., Xu, Y., de St Groth, B.F., Schofield, P., Christ, D., Milner, B., et al. (2020). Mapping the extent of heterogeneity of human CCR5+ CD4+ T cells in peripheral blood and lymph nodes. AIDS 34, 833-848.

Zaunders, J.J., Munier, M.L., Seddiki, N., Pett, S., Ip, S., Bailey, M., Xu, Y., Brown, K., Dyer, W.B., Kim, M., et al. (2009). High levels of human antigen-specific CD4+ T cells in peripheral blood revealed by stimulated coexpression of CD25 and CD134 (OX40). J Immunol 183, 2827-2836. 
bioRxiv preprint doi: https://doi.org/10.1101/2022.01.30.478400; this version posted February 1, 2022. The copyright holder for this preprint (which was not certified by peer review) is the author/funder, who has granted bioRxiv a license to display the preprint in perpetuity. It is made available under aCC-BY-NC 4.0 International license.

1331 